First publ. in: Aquatic Conservation: Marine and Freshwater Ecosystems 13 (2003), 6, pp. 507-549

\title{
The determination of ecological status in shallow lakes - a tested system (ECOFRAME) for implementation of the European Water Framework Directive
}

\begin{abstract}
BRIAN MOSS ${ }^{\mathrm{a} *}$, DEBORAH STEPHEN $^{\mathrm{a}}$, CRISTINA ALVAREZ $^{\mathrm{b}}$, ELOY BECARES $^{\mathrm{b}}$, WOUTER VAN DE BUND ${ }^{c}$, S.E. COLLINGS ${ }^{\mathrm{a}}$, ELLEN VAN DONK ${ }^{\mathrm{c}}$, ELVIRA DE EYTO ${ }^{\mathrm{d}}$, TÕNNU FELDMANN ${ }^{\mathrm{e}, \mathrm{f}}$, CAMINO FERNÁNDEZ-ALÁEZ ${ }^{\mathrm{b}}$, MARGARITA FERNÁNDEZALÁEZ $^{\mathrm{b}}$, ROB J.M. FRANKEN ${ }^{\mathrm{g}}$, FRANCISCO GARCÍA-CRIADO ${ }^{\mathrm{b}}$, ELISABETH M. GROSS ${ }^{\mathrm{h}}$, MIKAEL GYLLSTRÖM ${ }^{\mathrm{i}}$, LARS-ANDERS HANSSON ${ }^{\mathrm{i}}$, KENNETH IRVINE $^{\mathrm{d}}$, AIN JÄRVALT ${ }^{\mathrm{e}}$, JENS-PEDER JENSEN ${ }^{\mathrm{j}}$, ERIK JEPPESEN ${ }^{\mathrm{j}, \mathrm{k}}$, TIMO KAIRESALO ${ }^{1}$, RYSZARD KORNIJÓW ${ }^{\mathrm{m}}$, TEET KRAUSE ${ }^{\mathrm{e}, \mathrm{f}}$, HELEN KÜNNAP ${ }^{\mathrm{e}}$, ALO LAAS ${ }^{\mathrm{e}}$, EVI LILL ${ }^{\mathrm{e}}$, BOGDAN LORENS ${ }^{\mathrm{n}}$, HELEN LUUP ${ }^{\mathrm{e}}$, MARIA ROSA MIRACLE ${ }^{\mathrm{B}}$, PEETER NÕGES ${ }^{\mathrm{e}, \mathrm{f}}$, TIINA NÕGES ${ }^{\mathrm{e}, \mathrm{f}}$, MIRVA NYKÄNEN ${ }^{1}$, INGMAR OTT $^{\mathrm{e}}$, WOJCIECH PECZULA ${ }^{\mathrm{p}}$, EDWIN T.H.M. PEETERS ${ }^{\mathrm{g}}$, GEOFF PHILLIPS ${ }^{\mathrm{q}}$, SUSANNA ROMO ${ }^{\circ}$, VICTORIA RUSSELL ${ }^{\mathrm{a}}$, JAANA SALUJÕE ${ }^{\mathrm{e}, \mathrm{f}}$, MARTEN SCHEFFER $^{\mathrm{g}}$, KLAUS SIEWERTSEN ${ }^{\mathrm{c}}$, HALINA SMAL ${ }^{\mathrm{r}}$, CLAUDIA TESCH $^{\mathrm{h}}$, HENN TIMM $^{\mathrm{e}}$, LEA TUVIKENE $^{\mathrm{e}}$, ILMAR TONNO ${ }^{\mathrm{e}, \mathrm{f}}$, TAAVI VIRRO ${ }^{\mathrm{f}}$, EDUARDO VICENTE ${ }^{\circ}$ and DAVID WILSON ${ }^{\mathrm{a}}$

${ }^{a}$ School of Biological Sciences, Derby Building, University of Liverpool, Liverpool L69 3GS, UK; ${ }^{\mathrm{b}}$ Instituto de Medio anbiente, La Serna 56, 24007, Leon, Spain; ${ }^{\mathrm{c}}$ National Institute of Ecology, Centre for Limnology, 1299, 3600 BG, Maarssen, 3631 A Nieuwersluis, The Netherlands; ${ }^{\mathrm{d}}$ Department of Zoology, University of Dublin, Trinity College, Dublin 2, Ireland; ${ }^{\mathrm{e}}$ Estonian Agricultural University, Institute of Zoology and Botany, Võrtsjarv Limnological Station, 61101 Rannu, Tartu County, Estonia; ${ }^{\mathrm{f}}$ University of Tartu, Institute of Zoology and Hydrobiology, 46 Vanemuise Str., 51014 Tartu, Estonia; ${ }^{\mathrm{g}}$ Aquatic Ecology and Water Quality Management Group, Wageningen University, PO Box 80806700 DD Wageningen, The Netherlands; ${ }^{\mathrm{h}}$ Fachbereich Biologie, Limnologisches Institut, Postfach M 659, University of Konstanz - 78547, Konstanz, Germany; ${ }^{\mathrm{i}}$ Dept of Limnology, University of Lund, Lund, Sweden; ${ }^{\mathrm{j} D e p a r t m e n t}$ of Freshwater Ecology, National Environmental Research Institute, Vejlsøvej 25, Silkeborg, Denmark; ${ }^{k}$ Department of Botanical Ecology, University of Aarhus, Norlandsvej 63, 8230 Risskov, Denmark; ${ }^{1}$ Department of Ecological \& Environmental Sciences, University of Helsinki, Niemenkatu 79, FIN-15140 Lahti, Finland; ${ }^{\mathrm{m}}$ Department of Hydrobiology and Ichthyobiology, University of Agriculture in Lublin, Lublin 20-950, Poland; ${ }^{\mathrm{n}}$ Department of Ecology, Maria Curie Sklodowska University, Lublin, Poland; ' Área de Ecología, Faculdad Biología et Investigación, Campus Burjasot, 46100 Burjasot, Valencia, Spain; ${ }^{\mathrm{p}}$ Department of Botany and Hydrobiology, Catholic University of Lublin, Lublin, Poland; ${ }^{\mathrm{q}}$ Environment Agency, UK; ${ }^{\mathrm{r}}$ Institute of Soil Science and Environment Management, University of Agriculture in Lublin, Lublin, Poland
\end{abstract}

\footnotetext{
*Correspondence to: Prof. Brian Moss, School of Biological Sciences, Derby Building, University of Liverpool, Liverpool L69 3GS, UK. E-mail: brmoss@liverpool.ac.uk
} 


\begin{abstract}
1. The European Water Framework Directive requires the determination of ecological status in European fresh and saline waters. This is to be through the establishment of a typology of surface water bodies, the determination of reference (high status) conditions in each element (ecotype) of the typology and of lower grades of status (good, moderate, poor and bad) for each ecotype. It then requires classification of the status of the water bodies and their restoration to at least 'good status' in a specified period.

2. Though there are many methods for assessing water quality, none has the scope of that defined in the Directive. The provisions of the Directive require a wide range of variables to be measured and give only general guidance as to how systems of classification should be established. This raises issues of comparability across States and of the costs of making the determinations.

3. Using expert workshops and subsequent field testing, a practicable pan-European typology and classification system has been developed for shallow lakes, which can easily be extended to all lakes. It is parsimonious in its choice of determinands, but based on current limnological understanding and therefore as cost-effective as possible.

4. A core typology is described, which can be expanded easily in particular States to meet local conditions. The core includes 48 ecotypes across the entire European climate gradient and incorporates climate, lake area, geology of the catchment and conductivity.

5. The classification system is founded on a liberal interpretation of Annexes in the Directive and uses variables that are inexpensive to measure and ecologically relevant. The need for taxonomic expertise is minimized.

6. The scheme has been through eight iterations, two of which were tested in the field on tranches of 66 lakes. The final version, Version 8, is offered for operational testing and further refinement by statutory authorities.
\end{abstract}

KEY WORDS: lakes; Water Framework Directive; typology; ecotypes; ecological status; quality

\title{
INTRODUCTION
}

The European Water Framework Directive (Directive 2000/60/EC of the European Parliament and of The Council of 23 October 2000 establishing a framework for Community action in the field of water policy) is potentially the most significant piece of legislation ever to be enacted in the interests of conservation of fresh and saline ecosystems (Pollard and Huxham, 1998). It seeks to replace legislation that has concentrated on emission standards for water quality, with little reference to ultimate ecological consequences. Its approach is to work backwards from ultimate targets for ecological quality to whatever legal and practical measures are necessary to achieve these targets. It also uses biological measures to a greater extent than previously, when water quality based largely on chemical determinands has been emphasized. The distinction between water quality and ecological quality is very considerable and systems currently used to establish the former are only a small part of those needed for the latter.

The Directive requires catchments to be managed in a holistic way, reflecting the connectedness that exists between the landscape and its uses, and the nature of the water that runs off it into flowing and standing waters and groundwaters and eventually to estuaries and the sea. The ultimate effectiveness of this measure will be reflected in the degree to which aquatic habitats are restored, over the next 15 years and beyond, to 'good' ecological status. 'Good ecological status' is the ultimate target and 'status' as used in the Directive is synonymous with 'quality'. The Directive requires, first of all, a typology among flowing, standing, transitional (estuarine) and coastal waters. In each of these general groups, types, ('ecotypes' is the term used in the Directive), must be defined and reference conditions (or 'high status') for each type determined. Then, for each ecotype, a classification system must be established in which deviations from this high quality status must be determined.

These classes are called 'good', 'moderate', 'poor' and 'bad' and must be determined by the use of biological and chemical characteristics with hydromorphology appropriate to achievement of these 
chemical and biological characteristics. The Directive lists the characteristics that must be assessed but gives only general guidance as to the nature of these levels of quality. High status is defined in the Directive such that there are 'no, or only very minor anthropogenic alterations' to the chemistry, physics, morphology and hydrology of the water body and that values of biological quality elements 'reflect those normally associated with that type under undisturbed conditions, and show no, or only very minor, evidence of distortion'. High status is thus very close to pristine conditions.

European Directives indicate the spirit of legislation that must be put into operation through national legislation by Member States. Their effect may be weakened by the use of derogations built into the Directives in the process of their being agreed by all States in the European Parliament. Cost of remedial action and of monitoring is also an issue. Inevitably, faced with many demands on their budgets and the balance of lobbying by vested interests of all kinds, governments are faced with much compromise and the degree to which there might be delays in the enactment of Directives becomes a highly political issue. Conservation is likely to be a major loser as a result of these influences. Uncertainties about how to fulfil the intentions of Directives may also delay implementation. The Water Framework Directive is especially vulnerable to this. It is complex legislation attempting to measure what is inherently very difficult, for degrees of ecological quality are not absolute but matters of judgement. This paper contributes a tool to help overcome at least this problem.

There are at least two approaches to establishing a system for measuring ecological status. The first is to discuss it extensively among the 'competent authorities', the statutory agencies charged with implementing the Directive, in the hope that some wide consensus may emerge, and then attempt to create common systems for measuring it. At present numerous meetings are being held throughout Europe in the hope of achieving this. Every European country has some scheme for reaching some of the objectives of the Directive and each is attempting to incorporate its existing schemes into new systems to fulfil the greater ends of the Directive. This is understandable, given the accumulated data sets on water quality against which future change must be assessed. Likewise, bodies (10 working groups of the Strategic Co-ordination Group) have been set up by the European Commission to find common approaches.

However, no existing scheme is entirely satisfactory for none has been set up to measure ecological status as opposed to water quality. For rivers there are some schemes which take into account more than water chemistry (for example RIVPACS (Wright et al., 2000); SERCON (Boon, 2000) and River Habitat Survey (Raven et al., 1997)) but there are no equivalents for lakes. General approaches to monitoring water quality are often vested in the ultimate solution of the nineteenth and early twentieth century crisis of gross organic pollution by raw sewage (Hynes, 1970; Kristensen and Hanson, 1994). They have little to say about the current problems of eutrophication, acidification, introduced species, engineering damage, water abstraction and pollution by metabolically powerful trace organic substances, all of which are central to the restoration of good ecological status. New philosophies, created by modern problems, demand new brooms.

It is perhaps then necessary to learn from previous schemes but go back to ecological principles and current scientific understanding and create a fresh, simple scheme that will be immediately workable. One way to do this is to bring together groups of expert ecologists, with practical knowledge of the systems, to agree on schemes that make ecological sense and then to test them to discover and solve practical operational problems in an iterative way, until a workable solution is reached. This paper concerns such an approach and records the process of developing a usable scheme, in the first instance for shallow lakes, but potentially extendable to all lakes.

\section{THE DIRECTIVE AND LAKES}

\section{Establishing a typology}

Standing waters are one of the four main surface water categories to be dealt with under the Directive. The first problem is to establish a typology, the second a system of measuring ecological status. Annex II of the 
Directive suggests two approaches to a typology of lakes. System A is given in detail and embraces 25 biogeographical regions, three categories of altitude, four for area, three for depth and three for immediate geology (organic, siliceous, calcareous). This gives a total of 2700 potential ecotypes, although not all altitudinal, depth, areal and geological combinations might occur in each biogeographical region. A realistic assessment might give more than a thousand ecotypes however. Alternatively, System B allows States to propose a different system, as long as it gives at least as good resolution as System A and suggests some other variables that might be used to establish the typology.

Two issues are important in the establishment of a typology. First, it should not be so complicated that conditions of high ecological status cannot easily be defined for every one of the ecotypes. Second, and most importantly, it should use only characteristics that are geographical and do not overlap with the variables used in measuring ecological status, otherwise a very confused system will result. For lakes, System A as proposed is undoubtedly too complex. It uses only geographical features but it omits some characteristics, such as climate and conductivity, that might be more valuable in establishing a limnologically meaningful scheme than the ones it proposes.

System B, as exemplified in Annex II, poses a very great danger in that it suggests nutrients might be used as a variable in establishing the typology. Clearly, changing nutrient loading is one of the key characteristics affecting ecological status and it would be most inadvisable to use it as a component of a typology. System $\mathrm{B}$, however, offers the flexibility of producing a simpler, practicable, typology and, importantly, has the option of including small lakes, many of which are of considerable amenity and conservation importance. System A excludes these by using a minimum lake area of 50 ha.

\section{CLASSIFICATION OF ECOLOGICAL STATUS}

The Directive requires the establishment of reference conditions (high ecological status) for each of the ecotypes in the typology. These reference conditions can be determined from existing sites, from models, from palaeolimnological reconstructions and from expert judgement or from some combination of these. This is the closest the Directive comes to establishing general criteria that are close to objective because it defines high ecological status as a state insignificantly influenced by human activity. Thereafter the establishment of degrees of quality can only be through expert judgement, there being no absolute meanings of good, moderate, poor and bad. One of these terms is itself used in its own definition in Annex $\mathrm{V}$ of the Directive, thus offending a basic principle of lexicography.

Establishment of the reference conditions is not easy for there are few, if any, such sites available in Europe for all but polar and montane areas and even there the incidence of climate warming, increased ultra violet exposure (Sommaruga-Wögrath et al., 1997) and air-borne pollutants make it unlikely that truly high status sites exist. The use of multivariate data analysis on large data sets from many lakes, despite

much investment, and faith in it as an objective way of determining groupings of sites, cannot be used for determining reference conditions. Such methods do give groupings, albeit often not very tightly defined, but because the lakes from which the data are derived have been subject to varied degrees of change from a variety of sources, the groupings are only artefacts of the individual states of impact at the time the data were collected and can have no absolute value.

Palaeolimnology (Vallentyne, 1969) has developed considerably during the last decade, not least by development of training sets and transfer functions allowing reconstruction of changes in variables such as $\mathrm{pH}$, concentration of total phosphorus, salinity, abundance of planktivorous fish, coverage of submerged macrophytes and relative contribution of various algae (Bennion et al., 1995, 1996; Jeppesen et al.,1996, 2001a; Sayer, 2001). Reconstruction of some chemical variables, such as pH (ter Braak and Van Dam, 1989), which change on logarithmic scales, has been very reliable but for other chemical variables, which change arithmetically, the reconstructions are often subject to variabilities that cover more than one order 
of magnitude (Bennion et al, 1995, 1996; Sayer, 2001) and this is too great for precise reconstruction of reference conditions. The major changes in nutrient status that have occurred in British rural catchments since before World War II, for example, have embraced only a doubling, on average, in nutrient loadings (Johnes et al., 1996). However, there is great potential for modern palaeolimnogical reconstructions in helping identify the general characteristics of reference conditions. The techniques are improving rapidly so that more precise reconstructions will eventually be possible especially by using arrays of different organisms in sediments (multi-proxy approaches), calibrated from similar arrays under current conditions.

Determination of reference states is therefore currently best approached through a combination of expert judgement based on experience, available data, hindcasting using export coefficient models (Johnes, 1996) and palaeolimnology. The process is likely to depend a great deal on the accumulation of experience and integration from all these lines of evidence rather than on a statistically rigorous procedure. It therefore needs the consensus of groups of well informed ecologists.

In reconstructing lesser ecological quality states, there are again at least two approaches. One is to define values for chemical and biological variables that are supposed to be fixed norms for each state and to compile the whole from the sum of these. This is the approach likely to be adopted naturally by organizations which have managed water quality in the past, largely from the viewpoint of chemical compliance.

There is, however, no single set of conditions that represents high ecological status in a given place. Ecosystems are complex and their characteristics mutually vary within large ranges, determined not only by external conditions such as weather and catchment characteristics but by internal processes. The uptake of substances by primary producers, their release by grazers and decomposers and the influence of predation on the grazers and on the predators by their own predators lead to an infinite number of normal combinations of values of thousands of measurable variables. Every ecosystem exists, even in the absence of human impacts, in many alternative states (May, 1977; Scheffer et al., 1993), sometimes transient, sometimes quasi-stable, none of which necessarily represents a superior quality to any of the others. Ecosystems cannot be prescribed by single formulae.

The second approach is to create a picture of the general characteristics of what an ecosystem would have in its high quality state. Overall structure is the most important common feature, the crucial stage on which ecological action takes place. The procedure is then to work back to prescribe the ranges of values of determinands that could correspond with this scenario. This approach acknowledges that any particular variable will be very likely to give hugely variant values when a single or only a few samples are taken and thus must use a range of variables as a set of insurance policies in arriving at a sensible assessment. This approach is inherently built into the Water Framework Directive by its stipulation of a range of characteristics that must be measured.

Because the Directive places a great deal of emphasis on the maintenance or restoration of 'good' ecological status, more importance attaches to defining this than to lesser states. Guidance given in Annex $\mathrm{V}$ (Table 1.2) for good status is very stringent: 'The values of the biological quality elements for the surface water body type show low levels of disturbance resulting from human activity, but deviate only slightly from those normally associated with the surface water body type under undisturbed conditions'. On this definition it is doubtful that very many current water bodies of good status still exist in Europe. A pragmatic approach will have to give considerable breadth to the definition of 'slightly'.

One solution, which accepts that much of Europe will remain generally heavily agricultural and frequently highly populated, is to use, for good status, the baseline state determined for comparison of current states in lakes by Moss et al. (1997) and subsequently developed. This proposed that a desirable baseline state would be one in which the land use was genuinely sustainable - that it would reflect natural climatic, topographic and geological conditions and not be a usage maintainable only by import of large quantities of energy and materials, that there would be no net accumulation of alien substances nor of high quantities of native substances, and that the currently most efficient technology be used to treat urban and 
Table 1. Annex V (Water Framework Directive) requirements for variables to be used in determining the ecological quality of lakes and prescribed minimal sampling intervals

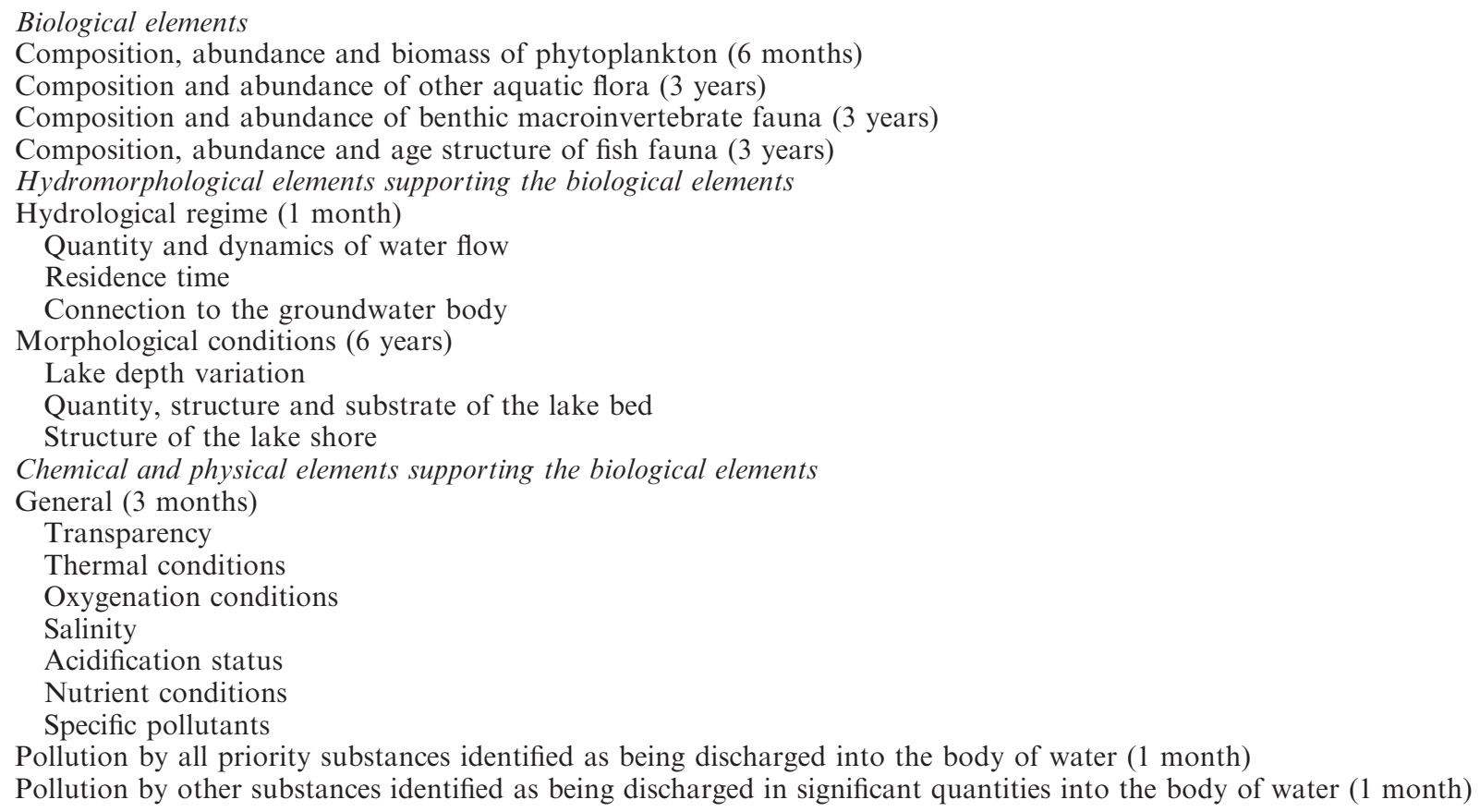

Several types of monitoring are listed in the Directive. For establishment of initial status (surveillance monitoring) and subsequent monitoring (operational monitoring) these frequencies are the minimal and sampling must cover at least one year when the intervals are less than one year.

industrial wastes also to meet these conditions. In practice, most of these conditions were met by the nature of land use prevalent in the early twentieth century, prior to the agricultural intensification that followed World War II.

\section{METHOD OF APPROACH}

These principles have been put into practice in developing a typology and a quality classification system for shallow lakes. These lakes were chosen because they are among the most complex ecologically of standing waters and the problems they pose for typology and classification could allow easy extension of the scheme to all lakes. The scheme was tested by sampling more than 100 lakes in 2 years to discover the practical difficulties, recording the time taken for sampling and processing and comparing the results with more informal judgements. All of the 12 laboratories involved have considerable experience in research on the ecology of shallow lakes and some have been very influential in revising an ecological view of these lakes in the past 30 years (Irvine et al., 1989; Jeppesen et al., 1990, 1998, 2001b; Scheffer et al., 1993; Moss et al., 1994, 1996, 1998; Van Donk and Gulati, 1995; Hansson et al., 1998; Scheffer, 1998).

The approach was to integrate experience, very large data sets accumulated by the National Environmental Research Institute, Denmark (Jeppesen et al., 1997, 2001b) and expert judgement, in a series of residential workshops, to create the typology with the express aim of making it both ecologically 
relevant and simple enough to be manageable, whilst also being applicable to all of Europe. It was created as a core scheme whose categories can be sub-divided to meet particular local conditions. However, this process was resisted in development because every such sub-division doubles the number of ecotypes in a geometric series. In the same workshops a series of scenarios was constructed of what conditions were envisaged as characterizing high quality for the 48 shallow-lake ecotypes of the final scheme.

Concurrently the variables which might best be used to characterize these scenarios were decided, with minimal redundancy but maximal probability of measuring features that contributed to the concept of ecological quality. The key feature in choosing variables had to be ecological significance. This may mean that some variables chosen are ones with high variability rather than high predictability. It is better to emphasize accuracy (in the statistical sense that variables assess what they are intended to assess) over using variables which can be rigorously predicted (high precision, often chemical determinands) but which are ecologically relatively unimportant. Indeed a variable that is relatively invariable is likely to be least important ecologically.

In 2000, following discussions in which over 100 variables were considered, more than 50 were measured on a series of 66 lakes to discover whether they had the anticipated predictive value and also to discover how long each measurement took. Every characteristic required by Annex V of the Directive was covered, sometimes directly, sometimes tangentially. The results were then examined and the range of variables trimmed down considerably. As many as possible were discarded on considerations of redundancy, cost or lack of sensitivity and the scheme was modified accordingly. In 2001 the evolving scheme was re-tested on a set of 66 lakes and again the results were reviewed to produce the final proposal, known as ECOFRAME Version 8. It is suggested that this be used as a starting point for examination under operational, as opposed to research, conditions.

There is no absolute way of determining the validity of any scheme proposing to measure degrees of ecological status below that of high ecological status. Assessments can only be compared among independent experts and not against any absolute standard, except in a qualitative way that compares conditions with those established for reference conditions. No single variable will be reliable in predicting ecological status because of the inherent variability of all biological variables. The scheme thus focuses on biological structure rather than on details of taxonomy of organisms, which also reduces the need for expert knowledge among users. Assessment must be on a group of variables because of this variability. Techniques developed for assessing water quality, dependent on the statistical variation in only a single variable, and therefore a rigorous calculation of probability of the measurement representing true conditions, are unlikely to be appropriate. How best to make assessments from the data collected is thus also considered.

\section{DESCRIPTION OF THE ECOFRAME SCHEME}

\section{Typology}

ECOFRAME typology is in accord with system B which uses only geographical characteristics and applies to shallow lakes (mean depth below $3 \mathrm{~m}$ ). At high status their productivity would be dominated by communities associated with the bottom, either of algae or of macrophytes and associated periphyton, rather than by phytoplankton. Extension of the scheme to all lakes is discussed later. The typology (Appendices 1,2) is applicable throughout Europe and is based on four climate categories (cold, cool, temperate and warm), defined by the period of annual ice cover (greater or less than two months) and the mean air temperature of the warmest month. These subsume considerations of latitude, longitude and altitude, listed in the Directive, into geographical components that can be more readily used to designate ecotypes, and cover the region from the Arctic to the Mediterranean. 
It then uses two lake area categories, with a threshold of 10000 ha $\left(100 \mathrm{~km}^{2}\right)$. This separates very large lakes, with major wind effects, from smaller lakes. There was no evidence that the ecological characteristics of shallow lakes differ fundamentally among lake areas below 10000 ha down to areas of a few hectares. There are, however, significant differences (owing much to stochastic factors such as chance of colonization and risk of drying out) in very small lakes (ponds) smaller than 1-3 ha. These are not necessarily included in the provisions of the Directive. They are excluded from System A but System B offers no minimal recommendation for area and many lakes of considerable conservation importance are much smaller than the 50 ha minimum for System A.

So far this gives eight basic categories of either large or small cold, cool, temperate or warm lakes. A further distinction is then made according to the catchment, into peat (organic soil)-based catchments, with more than $50 \%$ of the area covered by peat deposits, and rock-based catchments, with more than $50 \%$ of their area floored by rock or mineral-based soils. Peaty catchments give brown waters with distinctive ecological features. Within these categories, three classes of conductivity are used. These reflect water supplied from acid peat or poorly weathered rocks $\left(<100 \mu \mathrm{S} \mathrm{cm}^{-2}\right)$, from base-rich peat or soils, often from underlying calcareous rocks $\left(101-800 \mu \mathrm{S} \mathrm{cm}^{-2}\right)$ and waters with some saline influence, either from natural percolation of marine-derived groundwaters or from high evaporation or even endorheicity $\left(>800 \mu \mathrm{S} \mathrm{cm}^{-2}\right)$.

The core typology has 48 ecotypes ( 4 climate $\times 2$ area $\times 2$ catchment substratum $\times 3$ conductivity). Competent authorities (those responsible for administering the provisions of the Directive) in specific areas might wish to build on it by sub-dividing the existing categories. Those in boreal regions, for example, may wish to sub-divide the peat-based catchments to reflect different areas of peat coverage and the consequent effects on the concentrations of brown substances in the water. Mediterranean countries may wish to subdivide the $>800 \mu \mathrm{S} \mathrm{cm}^{-1}$ conductivity category to reflect the variety of endorheic basins which they have. Many countries may wish to use more area categories, including one for very small lakes, because these often have very significant nature conservation significance. The scheme is open-ended and provided that sub-divisions of the core categories stipulated here are used, should remain robust and comparable across member states.

\section{Ecological state classification - scenarios of quality}

The catchments of lakes in Europe would, under pristine conditions, be dominated by tundra in the polar regions, boreal forest in the far north, broad-leaved forest centrally and to the west, shrubby vegetation in the south and grasslands towards the south-east and east. These landscapes would be unmanaged for the production of timber or for services such as grazing. Almost nowhere will this situation persist, though the tundra and boreal regions still bear large tracts of only lightly managed vegetation, with lakes that could still be considered of high status under the definitions of the Directive.

The productivity of shallow lakes is dominated under pristine conditions by bottom vegetation. Sometimes, in the short growth season of the polar regions, this comprises algal communities with only few macrophytes, largely isoetids or charophytes depending on local conditions. Elsewhere productivity is dominated by macrophytes with associated periphytic algae. Key to high or good ecological status, therefore, is that the lake must still be dominated by stands of appropriate bottom-living primary producers.

The nature of the community can be changed by impacts such as acidification, which will lead to a dominance of Sphagnum and certain very acid-tolerant species such as Juncus bulbosus, or eutrophication. The latter will lead to greater growths of large competitive macrophytes, as opposed to the shorter charophyte or isoetid species (Blindow, 1992; Moss, 1999) that can persist if they are not forced to compete with increasing crops of periphyton or phytoplankton. A suite of mechanisms, including nitrogen competition, allelopathy and provision of refuges for animals that graze periphyton and phytoplankton combines to preserve the plant communities (Moss, 1999). The concept of good ecological status is thus 
that there should also be persistence of plant communities of sufficient diversity that a single species of the main growth forms - floating leaved and totally submerged - does not predominate.

As impacts increase, only the more tolerant species persist, often restricted to a very few floating-leaved species of nymphaeids or lemnids or of Sphagnum. This is considered to mark conditions of moderate ecological status. Major switches then occur as impacts increase. Under acid conditions the water may become extremely clear as mobilized aluminium flocculates particles and precipitates phosphate but Sphagnum will persist. Poor status in acidified lakes will be marked by complete loss of fish and further reduced $\mathrm{pH}$. Under eutrophicated conditions, the mechanisms that stabilise the macrophyte communities will often fail and there will be a switch to phytoplankton dominance. This will mark the onset of poor condition in such lakes. Finally, bad conditions will be reflected in either an even greater reduction in $\mathrm{pH}$ in acidified lakes or a dominance by only one prominent species or bloom-forming species of phytoplankter for long periods in summer in eutrophicated ones.

Other impacts are likely, of course. These include development of shorelines for housing or marinas, introduction of exotic species, stocking for angling, toxic pollution, alteration of water levels, recreational damage, and many others. These have to be incorporated but many will be lake-specific rather than generic. For generic variables it is possible to stipulate absolute ranges to be expected but for other impacts assessment can best be made on the basis of relative degree of impact.

\section{Ecological status classification - variables used}

The Directive gives general guidance on the determination of ecological status. This has been translated into specific requirements for each ecotype, based on a minimum number of variables. Ultimately 28 were used (Appendices 1,2), some of which can be determined by a single visit to the lake.

The scheme was devised to reflect the sampling frequencies stipulated in the Directive. These are in general relatively low compared with the sampling carried out for ecological research purposes and this has meant that the scheme depends much less on the incidence of particular taxonomic categories than might be used with very frequent sampling. A sampling of phytoplankton every 6 months, for example, is unable to give data reliable enough to characterize a lake on the basis of representation of specific algal groups such as the cyanophytes, diatoms and green algae. To do this reliably, sampling every week or two weeks would be necessary and this would be extremely expensive. Reynolds (2002) even suggests that predictability is possible only at a range of 2 days or fewer.

Specific changes in zooplankton are equally frequent (Makarewicz and Likens, 1975). Financial and time resources will inevitably be limited for operation of the Directive. This will mean that rather few lakes can be considered if sampling is intensive, more if it is extensive. The spirit of the Directive in terms of river basin management is towards extensiveness and protection of the entire landscape rather than concentration only on a few sites of high conservation importance.

In testing the penultimate Version 7 of the scheme, a suite of variables was used that was modified in producing Version 8, on the basis of the results of testing. The general rationale for the variables used is explained below. Details of scoring for those variables discarded in drawing up Version 8 but for which data are recorded, are given in the caption to the appropriate table (Table 4). Appendix 1 gives details of the variables retained for Version 8. The appendix is thus a self-contained statement of the scheme, whilst the main text concentrates on the issues raised in testing the penultimate version.

\section{EXPLANATION OF THE VARIABLES USED FOR DETERMINING ECOLOGICAL STATUS}

Annex V of the Directive lists the categories shown in Table 1 as mandatory for determining ecological status in lakes, with the minimum sampling frequencies for the initial characterization of the status of a given site. Zooplankton is not mentioned in Annex V yet zooplankters are very important components of 
the ecological quality of shallow lakes (Hurlbert et al, 1971; Scheffer et al., 1993; Jeppesen et al., 1997, 1998) sometimes acting as keystone species which pivot quite different ecological communities and states. It is mystifying that they were left out of the Annex, but because the Directive does not exclude the option of adding variables, and because the credibility of any scheme for assessing ecological status of lakes would be undermined by their absence, measures of the zooplankton community have been included. The zooplankton also provides a surrogate, to some extent, for the influences of different fish communities and this will be very useful in instances where practical considerations make it impossible to obtain adequate data on fish. Member States will quite legally be able to omit zooplankton and some may take the view that any variable not specifically required in the Directive will be ignored, but this would be short-sighted. Other organizations may wish to use ECOFRAME or developments of it for lake assessments and might appreciate its ecological comprehensiveness. It might also be used for independent testing of any other nationally derived scheme.

The variables used in Version 7 and those finally chosen are shown in Table 2 and there follows an account of the reasons for choosing these variables and the considerations that were given in determining values for them for different ecological statuses in different ecotypes.

\section{pH}

$\mathrm{pH}$ is a key variable, being reduced by acidification and often increased by eutrophication. In high status lakes it is determined by the nature of the rainfall and snowfall and by the nature of the catchment. It varies greatly because it is influenced by the amount of photosynthesis during the day and may vary daily over two to three units, often reaching very high values in the late afternoon (Maberley and Spence, 1983; Madsen and Sand-Jensen, 1991). The ranges proposed reflect this diurnal variability and allow for sampling at any time of day. In high status, rock basin lakes, with poorly weatherable rocks, $\mathrm{pH}$ will be set by the nature of the rain and should not be below 5.5, which is approximately the $\mathrm{pH}$ of rain uninfluenced by anthropogenic acidification (Charlson and Rodhe, 1982). In boreal peaty basins, however, the ion exchange capacity of the peat can sometimes reduce the inflowing water to $\mathrm{pH} 4-4.5$.

Reduction in ecological status will result from atmospheric acidification, which will reduce $\mathrm{pH}$ to below 5.5 in rocky basins and sometimes down to 3 in peaty basins. Alternatively, in some basins late in the afternoon, $\mathrm{pH}$ may increase to 10 quite normally but will be increased to above 10 usually only where there has been eutrophication. The $\mathrm{pH}$ may vary greatly in plant beds, sometimes being increased by two or more units very close to the plants compared with the open water. Measurements should thus be made at the surface in open water as far as possible.

\section{Total phosphorus}

There is little need to elaborate on the key importance of phosphorus in lake ecology (Vollenweider, 1968; Dillon, 1975; Schindler, 1978; OECD, 1982). Total phosphorus (TP) has been chosen rather than the more

Table 2. Variables measured in testing Version 7 of the scheme and those finally selected for Version 8 . One variable used in Version 8 was examined in the testing of an earlier version and reinstated

Used in Versions 7 and 8

Physical and chemical : $\mathrm{pH}$, total $\mathrm{P}$, total $\mathrm{N}$, Secchi depth

Biological: Phytoplankton chlorophyll $a$; phytoplankton array; nature of the submerged and floating leaved plant community; submerged and floating-leaved plant dominance/diversity and abundance; ratio, by number, of large to all species of Cladocera; zooplankton to phytoplankton biomass (chlorophyll $a$ in Version 8) ratio; among macroinvertebrates associated with the submerged portions of emergent plants: percentage by number of predators; ratio of naidids to chironomids plus naidids and percentage by number of sensitive groups (Plecoptera, Ephemeroptera, Trichoptera, Naididae); fish community; fish biomass, piscivore to planktivore ratio.

Used in Version 8 but not in Version 7: ratio by number of oligochaetes to chironomids in soft sediments. 
easily measurable soluble reactive phosphorus because of the lability and considerable day-to-day variability of the latter. TP also varies but with much less amplitude. It may temporarily increase after heavy rain as suspended particles and soluble forms are washed into lakes or from resuspension on a windy day. It may also increase in summer as a result of release of phosphate from sediments under plant beds, even under good and possibly even high ecological status conditions.

Our values may be liberally high for truly high status conditions. They take account of the familiar (though judgementally derived) OECD (1982) ranges but eutrophication is now so widespread that we may have become inured to values that are generally high. More phosphorus is delivered to lakes from catchments that have weatherable, more calcareous rocks than those providing soft waters of low conductivity, but some karst (limestone or chalk) lakes have values as low as those for soft waters. In lakes of low conductivity, acidification mobilizes aluminium and results in flocculation of phosphorus-containing particles and precipitation of soluble phosphorus. The phosphorus concentrations to be expected in poor and bad acidified states in these lakes are thus lower than those expected of good to moderate status. The fact that a given range can indicate high status under some conditions and bad status under others is dealt with by use of conditional statements in Version 8.

\section{Total nitrogen}

Nitrogen is also widely recognized as a key nutrient but its available forms (mostly nitrate and ammonium) are very labile and do not lend themselves to classifications where sampling will be infrequent. In many lakes with high available nitrogen concentrations at the beginning of the growth season, values often become undetectable by mid-summer so the measurement of total nitrogen is proposed. Total nitrogen includes not only inorganic nitrogen but also organic nitrogen, which may be equally as abundant and is sometimes easily mineralized for growth by algae and plants. In high status lakes, little influenced by human activity, available nitrogen is very scarce. It is retained by the catchment vegetation and its compounds denitrified in the catchment soils. As the remainder enters the lakes it is further denitrified or taken up so that in pristine lake waters most of what is detected as total nitrogen is in particulate or dissolved organic form.

The values set for high status lakes are thus low but may still be too liberal. Nitrogen is readily increased by human activities, both through disruption of the catchment vegetation and through atmospheric pollution. The thresholds for status categories lower than 'high' are thus also relatively low and take into account the fact that macrophyte communities are very effective at uptake and denitrification. There is an argument that measuring both key nutrients is redundant and that measurement only of total $\mathrm{P}$ is sufficient. However, there are lakes that are naturally nitrogen limited and nitrogen may be more crucial in the determination of aquatic plant community diversity than total phosphorus. The two nutrients thus throw light on different ecological characteristics.

\section{Secchi depth}

The Secchi depth is a very convenient summary of many features of lakes but needs to be used carefully as it reflects the effects both of phytoplankton and inorganic and detrital turbidity as well as dissolved coloured substances in the water. In shallow lakes of high status the water should be very clear, with a dearth of suspended particles and the bottom visible at least at the mean depth. However, in acid peaty waters, such as are found in large areas of northern Europe, naturally occurring humic substances will reduce the transparency and the values in the scheme reflect this. Humic substances are also frequent in more alkaline waters but the very large concentrations emanating from acid peat are usually not found. In very large lakes, disturbance of bottom deposits will also tend to reduce Secchi disc transparency and allowance has been made for this. In lakes forming immediately at the feet of glaciers that are melting back, there will naturally be a very high turbidity from suspended clay. Such glacier-foot lakes are not included in this 
scheme because they are essentially disturbed riverine sites that have not yet attained their stable ecological characteristics.

Reductions in status may arise from eutrophication which will decrease the Secchi disc transparency. Where macrophyte populations are still present, these effects will be minimized by a range of mechanisms associated with maintenance of water clarity (Moss, 1999) and the Secchi disc transparency will change little. Only when the systems switch to phytoplankton dominance will there be a major decrease. Where acidification occurs and aluminium is mobilized, flocculation will increase the Secchi disc transparency and the water may be clearer at poor and bad status than it is at high status. Allowance is made for all of these factors in the scheme and because Secchi disc transparency is independently affected by several features, the thresholds of change have been kept to a minimum. In shallow clear-water lakes when the Secchi disc is visible on the bottom, use of a small disc in a dark tube (Schnell's tube) may be a useful alternative to a direct Secchi measurement, although the availability of a Schnell's tube has not been assumed in the scheme.

\section{Phytoplankton chlorophyll $a$}

Nutrient availability and phytoplankton chlorophyll $a$ concentration are closely related, but not perfectly, because of the influence of grazing, mixing and flushing in keeping chlorophyll concentrations below the potential set by nutrient availability. Because natural catchment vegetation in pristine areas tends to retain nutrients within the terrestrial communities (Pennington, 1984), the availability of nutrients to phytoplankton communities of all pristine lakes is naturally low. Biomass of the communities, reflected in chlorophyll $a$, will thus be low irrespective of the local geology, at high ecological status. Reduced status will result from increase in nutrient flow and increased chlorophyll $a$ concentrations in all but some very soft-water lakes. Such lakes may be influenced by eutrophication, especially from atmospheric sources of nitrogen, but reduced status is more likely to be caused by acidification which will reduce the chlorophyll $a$ through flocculation.

It is conceivable that a soft-water lake may suffer both acidification (from the atmosphere) and eutrophication (for example from village or farm sewage) simultaneously, in which case almost any combination of Secchi disc transparency, nutrients and chlorophyll could be found. Lakes in generally acidified soft-water regions showing symptoms of eutrophication may show a higher status than justified because of the mutual interaction of acidification and eutrophication.

\section{Phytoplankton community}

There are many general predictions about the nature of phytoplankton communities in different circumstances (Rawson, 1956; Reynolds, 1984, 1987). They are perhaps the best understood of all components of lake ecosystems. However, there is immense change in composition from week to week and the time taken to determine the separate components of phytoplankton biomass is large. The rapid turnover of the phytoplankton community, coupled with the costs of the determination, make it inappropriate to specify great detail in any practicable scheme.

In Version 7, categories were confined to the presence of a multi-species community compared with an essentially monospecific one of Cyanobacteria or Chlorococcales and this distinction was used to discriminate between poor and bad status when nutrients increase. Almost all lakes were expected to have, and did have, a multi-species community. In Version 8 this has been modified to use also observations of surface cyanobacterial blooms. Member States may wish to measure, for example, the proportion of cyanophytes and other major groups of phytoplankton, but the patterns are not simply predictable. A heavily eutrophicated system will not, for example, necessarily show large amounts of cyanophytes (Jensen et al., 1994), whereas a high status lake may have a high proportion of these algae at certain times (McGowan et al., 1999). Version 7 included, as part of the (more predictable) ratio of biomass of 
zooplankton to phytoplankton (McCauley and Kalff, 1981) a measure of total phytoplankton biovolume (see below) so that a method was developed for those competent authorities who might nonetheless wish to use components of the algal community. However, the time taken to make this estimate was very large, because of the need to measure cell size as well as cell count, and for Version 8 the ratio was converted to one of zooplankton biomass to chlorophyll $a$.

\section{Plant and phytobenthos community}

The submerged and floating-leaved plant/phytobenthos community, or its absence, is the key variable in shallow lakes as it determines much of the lake function (Jeppesen et al., 1998). Emergent macrophytes are also important and included below under the criteria for nature of the shoreline. There are three components to the assessment of the plant community: its general taxonomic status, diversity and abundance. The community is influenced in pristine conditions by the climate (through the length of the growing season), light penetration, the availability of sediment for colonization, which will tend to be greater in peaty and more calcareous basins, the nutrient status of the sediment and water, and the conductivity of the water. Six easily recognizable community categories have been defined (Appendix 1).

The presence of large amounts of humic substances, with their strong light-absorbing properties will tend to favour the taller-growing nymphaeid and canopy-forming communities in extreme cases, but in general the lower nutrient loading of high status conditions will be associated with low-growing communities of small plants. Acidification will tend to displace these in favour of Sphagnum. In general, only very soft-water lakes will be affected by acidification and all by eutrophication. Eutrophication will result in replacement with taller, more competitive elodeids and pondweeds. Eventually only stands of plants with most of their photosynthetic tissue at the surface - nymphaeids, lemnids and canopy formers like Myriophyllum spicatum - will be able to persist as potential periphyton and phytoplankton burdens increase.

Some existing schemes for assessing lake status use specific determinations of the plant community (Palmer et al., 1992). These require taxonomic expertise and a greater expenditure of time in sampling than the ecological community approach taken here. It is also not possible to specify unequivocally, particular species to particular states (Seddon, 1972), a problem that exists for all biological variables. There is much stochastic substitution possible. However, one human impact on lakes is the introduction of some alien species of plants, which may suppress the diversity of the native flora. This has been built in to considerations of plant diversity (see below) but does require the recognition of these species.

Because of the importance of plants in shallow lakes, two further measures of the plant community are included to ensure that sufficient weighting is accorded to plants. These are plant diversity and plant abundance. Measures are designed to be quick and cheap. In early testing several person-days could be needed for conventional estimates of macrophyte biomass. For Version 7 plant dominance was simply measured as multi-species or monospecies communities, but this was elaborated to predictions of total number of species for Version 8.

The biomass of plants is an important consideration but large quantity is not synonymous with high status. A degree of eutrophication can produce dense beds that are less diverse in other organisms than sparser beds. Dense beds, for example, can produce overnight deoxygenation and fish kills. Abundance can be measured precisely as PVI (percentage volume infested) but this takes a very long time to do properly. A rapid method was developed which involves inspection of an area about one tenth of that of the lake and simple use of a rake or grapnel. The plants are scored as in Appendix 1.

\section{Zooplankton ratios}

Ratios have proved more useful than absolute measures of zooplankton communities and two were used. The first is the ratio of numbers of large species of Cladocera (Daphnia, Eurycercus, Simocephalus, Sida, Diaphanosoma, Holopedium, Leptodora, Polyphemus) to total numbers of Cladocera including the small 
species (all others). The second is the ratio of crustacean zooplankton biovolume (or biomass) to phytoplankton biovolume (or biomass). To compromise between the expense of making these measurements (which is very high) simple counts were used together with standard tables of average biovolume for each species derived from the literature. This gave adequate estimates for the zooplankters, despite the range of variation in size brought about through predation, but not for phytoplankters which had to be individually determined at the cost of much time. Consequently, for Version 8 a zooplankton biomass to chlorophyll $a$ ratio has been specified.

In lakes at high ecological status, there is a larger proportion of large Cladocera, which find refuges from fish predation among the plant communities. Where plants are lost (low quality states) in all lakes, large zooplankters become much less frequent. There are, however, indications that large species are relatively less abundant in pristine warm lakes perhaps because of the multiple recruitment of small fish (Lazzaro et al., 1992; Lazzaro, 1997). The scheme recognizes these features.

The ratio of zooplankton biovolume to phytoplankton biovolume or chlorophyll $a$ gives an independent measure of the influence of the zooplankton and also includes copepod zooplankton as well as cladoceran zooplankton. Inclusion of rotifers did not increase the usefulness of the ratio, but increased the costs of determining it. Ratios tend to be high where the zooplankton community is supported by the refuges given by the structure provided to the ecosystem by plants, which in turn tend to suppress phytoplankton production through mechanisms which include maintenance of high numbers of large efficient grazers within these refuges.

\section{Macroinvertebrates}

Macroinvertebrate communities are very varied, not only between lakes but also within lakes. There are many possible within-lake communities, but few that can be guaranteed to be present, for comparative purposes, in all lakes. Sampling may be expensive because of the considerable heterogeneity of distribution of the animals. A range of different sorts of samplers, of different efficiencies and characteristics, may be needed for particular conditions. Sediment is generally present in all lakes but may be sparse in the littoral zones of rocky basins. The sedimentary benthos has been used, historically, to characterize lakes (Berg, 1938; Brinkhurst, 1974; Saether, 1979; Brinkhurst and Cook, 1980; Wiederholm, 1980; Bazzanti and Seminara, 1986; Johnson and Wiederholm, 1989). Many of these classifications depend on good taxonomic expertise, though some are simple, but a great deal of time is usually needed for sorting the samples. For other macroinvertebrate communities there are few systematic data that can be used to formulate hypotheses concerning relationships with other features in lakes. Though the Directive requires assessments of macroinvertebrates, the complexity of their communities and the variety of their habitats made their use extremely difficult in assessing ecological status.

Simplicity was considered desirable so this component was best assessed, not by using submerged plants, which might be absent, but by using the emergent macrophytes which fringe virtually all lakes to some extent. Their submerged stems can be easily sampled and the animals scraped off. Thereafter, because of the taxonomic variety of the community, it became difficult to predict characteristics of ecological status at the generic or species level but, as with zooplankton ratios, using families and indicators of functional status are probably most reliable.

Three such variables, derived from the invertebrate community of emergent macrophytes, were used: the percentage of individuals of the family Orthocladiinae among the chironomid larvae present (in Version 7 only); the ratio of numbers of the oligochaete Naididae to the sum of Naididae and total chironomids; the percentage of predators among the assemblage; and the percentage of taxa (Plecoptera, Ephemeroptera, Trichoptera, Naididae) particularly sensitive to eutrophication and deoxygenation (Macan, 1963; Learner et al.,1978; Uzunov, 1982). The Orthocladiinae are characteristic of highly oxygenated waters and thus tend to reflect high status (Armitage et al., 1995), as does a high ratio of Naididae to chironomids. A greater 
proportion of invertebrate predators is expected in high status lakes, because of the refuge structure against fish predation provided by the plants (Diehl and Kornijów, 1998). In high status lakes, abundance of fish is expected to be low, thus minimizing fish predation pressure on larger invertebrates (Kajak et al., 1980), among which predators are prominent. In warm lakes these ratios tend to be reduced by the naturally lower oxygen content of such waters and this is reflected in the scheme.

The sorting of Orthocladiinae from other chironomids took an unacceptable length of time and substantial taxonomic expertise where small instars were present. The Orthocladiinae to total chironomid ratio was thus discarded in Version 8. However, following discard at an earlier stage, the ratio of oligochaetes (largely Tubificidae) to chironomids in soft sediment samples was reinstated. Partly this was because all the ratios show considerable variation when only a limited number of samples can be taken, because of the extreme heterogeneity of animal distribution, so that the more ratios measured, the more likely is the average picture to reflect ecological conditions. Partly it was because the long tradition of using this community in applied limnology (Chandler, 1970; Brinkhurst, 1974; Saether, 1979; Wiederholm, 1980) will result inevitably in a wish for its use by competent authorities, irrespective of need.

\section{Fish community}

The Directive specifically asks that information on the fish community be used. The fish community will need to be specified locally because of the substantial biogeographic variation throughout Europe. Some lakes of high status will have no fish community because they have been isolated since the last glaciation and this will have to be determined locally. If there is a natural fish community, it should have certain general characteristics at high status. There will be locally characteristic native piscivores present, either salmonid, percid or esocid, whilst aggressive introduced species (Pimental et al., 2001) will be absent. Thus, introductions of common carp (Cyprinus carpio - from Asia) (Cahn, 1929) or rainbow trout (Onchorhyncus mykiss - from North America) will downgrade the status of a site, as will introductions of ruffe (Gymnocephalus cernua) from lowland to upland lakes within the UK or the introduction of the non-native roach (Rutilus rutilus) to Irish lakes. Non-aggressive introductions, largely of curiosity value, such as those of the bitterling (Rhodeus sericeus) into the UK are not used to downgrade a site in the scheme. However, the long-term unpredictability of the damage caused by introduced species might prompt competent authorities to downgrade a site if any introduced species are present. This issue is relevant also to introduced plants and invertebrates.

\section{Fish biomass}

The former view that 'the more fish the better' is no longer consistent with an understanding of ecological quality. Fish can be extremely damaging either directly to macrophyte communities or indirectly through their predation on zooplankton and plant-associated invertebrate grazers. Data are now available on thresholds of biomass likely to cause damage (Moss et al., 1996) and these have been used in the scheme, so that decrease in quality is initially reflected in increased biomass. Total loss is also detrimental and may occur through acidification or nocturnal or sub-ice deoxygenation following eutrophication. In all cases the assumption is that fish would naturally be present in a lake but when the scheme is used in polar and montane regions, recognition is built in that many lakes there are naturally fishless. The biomasses quoted are for the entire fish community, including the young of the year, which are often excluded from fishery estimates. However, they may be very important, through their predation on zooplankton, for determining ecological status.

\section{Fish piscivore to zooplanktivore ratio}

This variable is valuable in itself but is also used as a surrogate for age distribution of the fish community, required by the Directive, which would otherwise be extremely difficult to specify in a usable way. It would 
also be very expensive to determine, because several fish species are present in most lakes. High quality, clear shallow lakes are characterized by relatively high biomasses of piscivores, reflecting oxygenation conditions as well as complex ecosystem structure. Poor quality lakes lose their predators (Jeppessen et al., 1997) allowing major increases in zooplanktivores. These usually skew the size and age distribution range towards smaller and younger fish. The biomass ratio of piscivores to zooplanktivores is thus a very good indicator of status. In warmer lakes, specialist piscivores may be scarcer, in favour of omnivores, and the ratio has been set lower in these lakes, but values are less certain because of the limited number of quantitative studies in such lakes. There may also be subtleties in the changes in acidified lakes because of lesser sensitivity of some piscivores to decreased $\mathrm{pH}$. However, in the absence of comprehensive data sets, this has not been incorporated into the scheme.

\section{Quantity and dynamics of water flow, residence time}

The hydrology of a particular site will be unique to that site. It will depend on the local rainfall and its timing and on the shape and size of the lake basin and the relative sizes of lake basin and catchment (the Directive uses the term 'river basin' instead of catchment, but catchment is used here to avoid confusion). It is not possible to state positively what the characteristics will be, therefore, for each ecotype. This is a problem for all the hydrological and morphological characteristics and some of the physico-chemical factors specified in Annex V of the Directive (Table 1). The problem can be solved by specifying absence of relevant impacts rather than absolute values of the variable.

The amount of water flow and the pattern in time in which it arrives, and hence the residence time, will all influence the ecology of a lake because they determine nutrient loading, the development of plankton, the maintenance of marginal fish spawning habitat and many other details of lake function. However, they also normally fluctuate to a considerable degree dependent on weather. There are notably dry and notably wet years in most locations and the biota will have been selected to accommodate these. Weather also changes steadily owing to natural climate changes and, at present and more rapidly, to anthropogenic change.

Water flows, however, can be more seriously influenced by diversion of inflows to irrigation projects or abstraction for water supply and these can influence ecological status (Davies et al., 1992). Adding water, in transfer schemes for water supply, could also be ecologically damaging for it usually brings in water of different chemical nature and may introduce alien organisms. The scheme allows for the characteristics of natural variation and potentially damaging effects of abstraction or addition by using the categories shown in Appendix 1. The same characteristics are used for residence time because residence time is strongly dependent, for a given morphometry of the lake basin, on water flow into it.

\section{Connection to groundwater}

Many lakes are parts of groundwater systems and receive inflows from the groundwater or discharge to it. Again the degree of connection will depend on the local circumstances and is not specifiable on the basis of ecotype. However, lakes significantly fed by groundwater may be denied their natural supply if the groundwater table is drawn down by abstraction for irrigation or water supply. The same terminology of Normal, Modified and Severely modified as for surface water hydrology is used with the definitions shown in Appendix 1.

\section{Lake depth variation}

Lake depth variation can be taken to mean either lake level variation or characteristics of the profile of the basin. The former usage is covered under the hydrological characteristics above and it is the latter characteristic that is considered here. The profile of the basin is determined by the way that it was originally 
formed coupled with subsequent sedimentation. The former determinant is lake-specific and cannot be specified on an ecotype basis.

Sedimentation is also naturally lake-specific, depending on the nature of the catchment, but can be influenced by human activities resulting in increased erosion of the catchment or increased in-lake production of sediment because of eutrophication. Change in sedimentation rate in sediment cores could thus be used as an index of ecological quality. The annual deposition should be low and approximately constant under high ecological status and would increase with most sorts of human activity.

Determining sedimentation rate is, however, very expensive, requiring coring and dating of the cored sediment. It does not lend itself to routine use. This characteristic is thus best measured indirectly (Appendix 1). Increased sedimentation almost always results from disturbance of the catchment by agriculture and hence the degree of conversion of the landscape to agriculture has been used as a measure. In this, grazing means intense pasture usage with fertilization and ploughing to create productive swards. Extensive grazing in unfenced, unfertilized pastures (as long as stocking levels have not been excessive in response to headage payment schemes) is considered to be much less damaging (Hornung et al., 1984). Such an interpretation of this variable also allows the important consideration of how the catchment has been modified to be reinforced.

\section{Quantity, structure and substrate of the lake bed}

This characteristic is also lake-specific and must be assessed by degree of disturbance. Lake beds may be of a variety of particle sizes, or rocky. They may be covered with emergent or submerged macrophytes. The latter characteristic is already being measured by the macrophyte community. In some disturbed lakes, sedimentation may occur and may, for example, cover gravel spawning sites for salmonid fish. Alteration of lake levels by abstraction or water transfer may also lead to erosion or exposure of the littoral sediments. This is covered by the above hydrological assessments.

However, sands or gravels or rocks and boulders may be removed from some lakes for provision of building aggregate or horticultural purposes (garden design features) and this will have adverse effects. The substrata removed may be highly specific and have a substantial effect on fish spawning. The allowable levels of disturbance (Appendix 1) are thus quite low because even 1\% of the lake area may be a substantial proportion of a particular critical substratum type. There may also be instances of dumping of soil or other materials into lakes as a result of road or other building activities. These too are allowed for in the scheme.

\section{Structure of the lake shore}

Lake shores are very varied and may include erosional bare shores and sheltered shores colonized by sequences of emergent and floating-leaved plants. There are many ecological interactions between these fringing wetlands and the open water, shown by chemical patterns, migrations of organisms and nesting and lurking sites for birds, both grazers and piscivores, that influence the open water communities.

The pattern is lake-specific and cannot be specified for ecotypes but again this characteristic can be assessed by degree of disturbance. Lake shores may be cleared for urban, marina, or angling development, and damaged by boating activity or feral grazing birds. There may also be invasions of exotic species - for example, Japanese knotweed (Fallopia japonica), giant hogweed (Heracleum mantegazzianum) or Himalayan balsam (Impatiens glandulifera). Shores may sometimes be concreted, or artificial beaches may be created by dumping sand. Some shores are modified as gardens and lawns fringe the water.

High ecological status will be marked by natural shores. Where wind fetch prevents sediment deposition, the shores will be rocky, gravelly or sandy but they will have some vegetation, even if it is only sparse isoetids or algal phytobenthos. On depositional shores there will normally be emergent vegetation, sometimes low growing carices or rushes, sometimes tall reeds (Phragmites, Typha, Scirpus, Cladium, Schoenoplectus), sometimes woodland of willow (Salix), alder (Alnus), birch (Betula) or spruce (Picea) or a 
variety of other species in warmer regions. It should nonetheless be easy to recognize naturally colonized shores, to perceive development and severe damage and to identify the rather vigorous introduced species. The assessment is thus made by the proportion of the shoreline occupied by development, or by damaged vegetation, or by alien plants (Appendix 1).

\section{Temperature}

Temperature regimes of lakes depend on the local climate, with considerable year-to-year variation with changes in weather. This is recognized in use of climate regions to provide the broad division of ecotypes that simplifies the typology. It is, however, not possible to specify precise local conditions except on an individual lake basis. Temperature can, however, be damaging where warm water is discharged from power stations. It is conceivable also that in volcanic areas like Iceland, diversion of thermal streams or springs from a lake basin for domestic heating purposes might result in a deviation from the natural thermal status of a particular lake. To allow for these possibilities the scheme uses categories (Appendix 1) that mirror those used for other locally-determined variables.

\section{Oxygen}

Oxygen concentration is of considerable significance in determining the nature of freshwater ecosystems. Oxygen is a highly labile substance, which varies greatly in concentration during the day and night and spatially within the water body, either as a result of natural temperature stratification or the complex patterns of water chemistry created by the growth of plants. Sometimes oxygen concentrations will fall to near zero in the lower parts of plant beds in lakes considered to have good ecological status.

A single measurement of oxygen as part of a lake survey is meaningless and proper characterization would require many measurements - spatial, diurnal and seasonal. Thus, although it would theoretically be possible to specify an oxygen regime for the different ecological states of each ecotype, it would be very expensive to determine as part of routine monitoring. However, the oxygen regime is a function of the nutrient supply and plant and algal growth and is indirectly specified by these variables in the scheme. What may nonetheless happen is that there are discharges of deoxygenating substances like raw sewage or animal slurry. This is more usual in rivers and streams but may occasionally occur in lakes. Its effects are incorporated by use of the categories in Appendix 1.

\section{Salinity}

Salinity is a measure of the total salts in the water and high salinities may be natural. There are categories of transitional waters and coastal waters in the Directive that reflect this. Fresh waters are conventionally considered to have salinities lower than $0.5 \mathrm{~g}$ total salts per litre, with mixtures of sea water and fresh water having larger values than this being considered brackish and falling into the transitional category. There are, however, waters close to the sea coast, with natural groundwater supplies of sea water, that do not fit the category of transitional waters, and inland saline waters in dry regions where closed basin (endorheic) lakes occur. These may be quite saline because of evaporation but with a salt composition that is different from that of sea water. Such lakes are usually small. To allow for these possibilities categories of lakes are included in the typology with conductivities greater than $800 \mu \mathrm{S} \mathrm{cm}^{-1}$.

There may, however, be pollution by salinity where sea water or industrial discharges enter lakes as a result of human activities. For example, pumped drainage of catchments close to the sea may suck sea water into the groundwater table and then discharge it into the lake, increasing the salinity quite considerably and having major ecological effects (Holdway et al., 1978; Bales et al., 1993). Equally it is conceivable that there may be diversions of fresh water for irrigation schemes that reduce the salinity of endorheic or coastal lakes below that which would be expected naturally. The reverse may occur where water is denied because of use 
for irrigation elsewhere, a common problem in Mediterranean regions. These possibilities have been allowed for by designation of the categories in Appendix 1.

\section{Pollution by priority substances}

Priority substances are potentially listed in Annex X of the Directive but none has so far been designated. Criteria for ecological status have thus not been determined but would follow those for pollutant substances listed in Annex VIII.

\section{Pollution by other substances}

Annex VIII of the Directive lists pollutant categories as follows: organohalogens, organophosphorus compounds, organotin compounds, carcinogens, mutagens and endocrine disruptors, persistent hydrocarbons and bioaccumulative organic toxins, cyanides, metals (presumed heavy) and their compounds, arsenic and its compounds, biocides and plant protection products, suspended material, eutrophicating substances and deoxygenating substances. Annex $\mathrm{V}$ gives guidance on the limits to be applied to these substances.

The cases of eutrophicating substances, deoxygenating substances and suspended solids have already been incorporated under the headings of total $\mathrm{P}$, total $\mathrm{N}$, oxygen and Secchi disc transparency. For the remainder, there exists a very long list of potential pollutants, many of which may be present from diffuse sources rather than overt discharges. Annex V states that for high status these substances should be present at close to zero concentrations, that are lower than the limits of detection of the most advanced techniques in use. For good ecological status, their concentrations should be lower than that determined as a "no observable effect concentration' (NOEC), scaled down by safety factors, by procedures detailed in Section 1.2.6 of Annex V.

These definitions cause a problem in that eutrophicating substances, deoxygenating substances, many heavy metals, and suspended solids are features of natural systems uninfluenced by humans. Indeed some of these substances are absolutely required by living organisms and the conditions stipulated in Annex V, Section 1.2.6, would mean that no ecosystem could exist. This is clearly an oversight in the drafting of the Directive and conditions for these substances have been dealt with in the scheme in such a way as to take account of this. For substances not falling into this category (recognized toxic pollutants) the scheme uses the stipulations of the Directive. However, the determination of the NOEC for representative species of each ecotype poses a major problem for competent authorities and some general compromise will be necessary, perhaps by using the lowest NOEC concentrations determined for any system in the first instance. The case of the heavy metals is particularly difficult as many of these are required metabolites and sensitivities to them cover a wide range. The pollutant substances are dealt with collectively in the scheme (Appendix 1).

\section{METHODS FOR SCHEME TESTING}

Common protocols for all sampling and analysis were agreed and established as far as possible. All sampling was carried out in late summer. Because the aim of the Water Framework Directive is to use biological variables to the greatest extent, summer sampling is mandatory but chemical variables were chosen that might be expected to vary least over the year, for example total phosphorus and nitrogen as opposed to available forms of these nutrients.

Six lakes were chosen from each of 11 countries (see Table 3) to give a range in each country from presumed high/good status to poor status based on experience from previous testing. The sample is thus not representative of the average state of Europe's lakes but includes about equal numbers of perceived high/ 
Table 3. Times taken to carry out sampling and analysis in testing a scheme for the assessment of ecological quality in lakes

\begin{tabular}{|c|c|c|c|c|c|c|}
\hline & $\begin{array}{l}\text { Fieldwork, } \\
\text { excluding fish }\end{array}$ & $\begin{array}{l}\text { Laboratory } \\
\text { chemistry }\end{array}$ & $\begin{array}{c}\text { Laboratory } \\
\text { biology excluding } \\
\text { fish }\end{array}$ & $\begin{array}{c}\text { Field and } \\
\text { laboratory } \\
\text { fish assessment }\end{array}$ & $\begin{array}{l}\text { Total excluding } \\
\text { fish assessment }\end{array}$ & $\begin{array}{l}\text { Total including } \\
\text { fish assessment }\end{array}$ \\
\hline UK & 8 & 3 & 7 & nd & 18 & na \\
\hline Ireland & 6 & 1 & 12 & nd & 20 & na \\
\hline Poland & 9 & 5 & 6 & 9 & 20 & 29 \\
\hline Netherlands & 7 & 1 & 12 & nd & 20 & na \\
\hline Estonia & 11 & 4 & 12 & 86 & 27 & 113 \\
\hline Sweden & 15 & 1 & 14 & 10 & 30 & 40 \\
\hline Germany & 12 & 2 & 28 & nd & 42 & na \\
\hline Spain & 9 & 6 & 42 & 3 & 52 & 55 \\
\hline Denmark & 18 & 1 & 46 & 29 & 65 & 94 \\
\hline Finland & 26 & 1 & 64 & na & 91 & na \\
\hline Mean & 12 & 3 & 24 & 27 & 39 & 66 \\
\hline
\end{tabular}

Values are in person-hours per lake and are averaged over six lakes sampled in each country on one occasion each in late summer. nd, not done; na, not applicable.

good, moderate, poor/ bad quality lakes. It was expected that few high status lakes would be found, though ones that were thought might fit this category were included.

Assessment was based as far as possible on variables that could be quickly determined in the field, though many samples required processing in the laboratory. Boats were used, despite the greater person-power and time needs, because an assessment was required of the plant community over a representative part of the lake and because plankton and chemical data are least variable in off-shore samples. Times taken for field work were recorded in person-hours with times for fishing operations recorded separately. Likewise, the person-hours required for laboratory processing were noted.

Chemical determinands were measured, as was phytoplankton chlorophyll $a$, by standard methods generally used by competent authorities in the countries concerned. Phytoplankton community was counted on whole-water samples preserved in Lugol's iodine using inverted microscopes and a standard protocol designed to limit the time required to that needed to assess the overall biovolume. Zooplankton was sampled in the field using tube samplers which reached to the bottom, and pouring $10 \mathrm{~L}$ of water derived from samples pooled from five locations through a $50 \mu \mathrm{m}$ mesh net and subsequent preservation in $90 \%$ alcohol. Counts were made of the major taxa and converted to biomass using a standard scheme compiled from the literature. Biomass per animal varies with size, but measurement of individual animals is extremely time consuming and the increase in precision was not considered to be justified.

Plants were estimated in terms of community and abundance, using the criteria in Appendix 1, during a field visit. Macroinvertebrates were sampled by using a designed sampler in which a plastic tube was lowered over stems of emergent plants and the stem cut by shears so that the stem floated up into the tube and water was drained out through a $240 \mu \mathrm{m}$ mesh (Kornijów and Kairesalo, 1994). In practice, simple cutting and gentle handling sometimes proved more practicable. Four lots of 10 stems each were taken from different parts of the lake, and scraped free of animals by hand, which were preserved in alcohol for later examination under stereomicroscopes. For soft-bottomed communities, 10 random cores were taken to depths of at least $10 \mathrm{~cm}$ with a 5 -cm diameter corer under about $1 \mathrm{~m}$ of water. Sediment was sieved through a $240 \mu \mathrm{m}$ mesh before preservation of the animals in ethanol.

Fish proved a particular problem. The most reliable way of assessing the fish community is by fleets of gill nets of a wide range of mesh sizes. Gill netting, however, is destructive and socio-political considerations prevented its use in many countries. It was allowed only in Denmark, Finland, Estonia, 
Sweden, Spain and Poland, all countries with long traditions of consumption of freshwater fish. A standard protocol was used with $42 \mathrm{~m} \times 1.5$ or $0.75 \mathrm{~m}$ monofilament nylon nets comprising 14 mesh sizes in $3-\mathrm{m}$ section Lundgren nets. Mesh sizes ranged from 6.25 to $100 \mathrm{~mm}$. Nets were set close to shore and in mid-lake with the number of nets proportional to lake area, up to a maximum of eight nets. In Finland and Poland $30 \mathrm{~m} \times 1.5 \mathrm{~m}$ monofilament nylon nets with 12 mesh sizes $(5-55 \mathrm{~mm}$ ) in $2.5 \mathrm{~m}$ sections were used (Nordic nets). Nets were set in late afternoon and retrieved the following morning. Double fyke nets, $10 \mathrm{~m}$ long with cod ends of mesh size 8 and $5 \mathrm{~mm}$, were also used for benthic fish species. Catches were expressed as weight of fish caught per net-night.

In other countries, where fish are seen mainly in recreational angling terms, fish biomass could not be reliably measured, other methods such as seining being considered too unreliable, but information on fish community composition was obtained from such methods and from local knowledge.

There is an additional problem in that gill netting gives estimates in terms of catch per unit effort (CPUE), whilst the ecologically meaningful unit is absolute biomass per unit area. Calibration of CPUE is difficult. Criteria in Version 8 of the scheme are given in absolute biomass terms and it is accepted that values for this variable will be crude. This will be either because inefficient fishing methods that are capable of giving a weight per unit area value have been used, or because gill netting results can only be converted to absolute measures by comparison with these less efficient measures. Unfortunately, gill netting hence offers no advantage unless the fishing effort can be rigorously standardized and criteria in the scheme expressed only as standardized CPUE. However, multiple mesh-sized gill netting, in such conditions, is by far the best method to obtain an overview of the fish community composition and size distribution.

\section{RESULTS}

Times taken to accomplish the field and laboratory work in testing Version 7 are shown in Table 3. These timings do not include travel between the base laboratory and the lake, which might add several personhours. Fieldwork, excluding that required for fishing, averaged 12 person-hours, with a wide variation, from 4-26. This reflects largely the size of lake, because logistics and boat crew size are greater for larger lakes as is also the time taken to examine the $10 \%$ area required for plant assessment. Laboratory chemistry, averaging 3 person-hours, ranged from 1-6. To some extent, this reflected differences among laboratories where a routine system for handling many water samples was available and those where the system had to be established for this project.

Biological analyses (average 24 person-hours per lake) took from 6 to 64 person-hours. To some extent this reflects difference in the richness of samples, but is mostly due to some laboratories having standard and very thorough procedures for biological analyses and being unable to reduce these standards in the interests of practicability. It also reflects degrees of experience among the personnel used, sometimes relatively inexperienced graduate students, sometimes technical staff with considerable knowledge. Many of these factors will also be present among the laboratories of competent authorities operating such schemes, so that the overall average for non-fish work of 39 person-hours or just over a standard person-week, is probably realistic for operational purposes.

Estimates for the time taken for fisheries work, available from five of the countries, varied nearly tenfold, again reflecting the number of persons necessary on different-sized lakes and the need in some cases to post guards overnight against theft of nets. On average, fish work alone took almost as long as all other work in the assessments, giving a final estimate of about 2 person-weeks to carry out the assessment on a single occasion. However, provisions of the Directive are that chemical assessments must be carried out at 3month intervals, and phytoplankton at 6-month intervals. This will increase the time required to assess the quality of a lake by up to a further 45 person-hours, giving a total of 118 person-hours (about 3 personweeks) per lake. In the initial determination of lake status for the Directive, an investment of the time of 


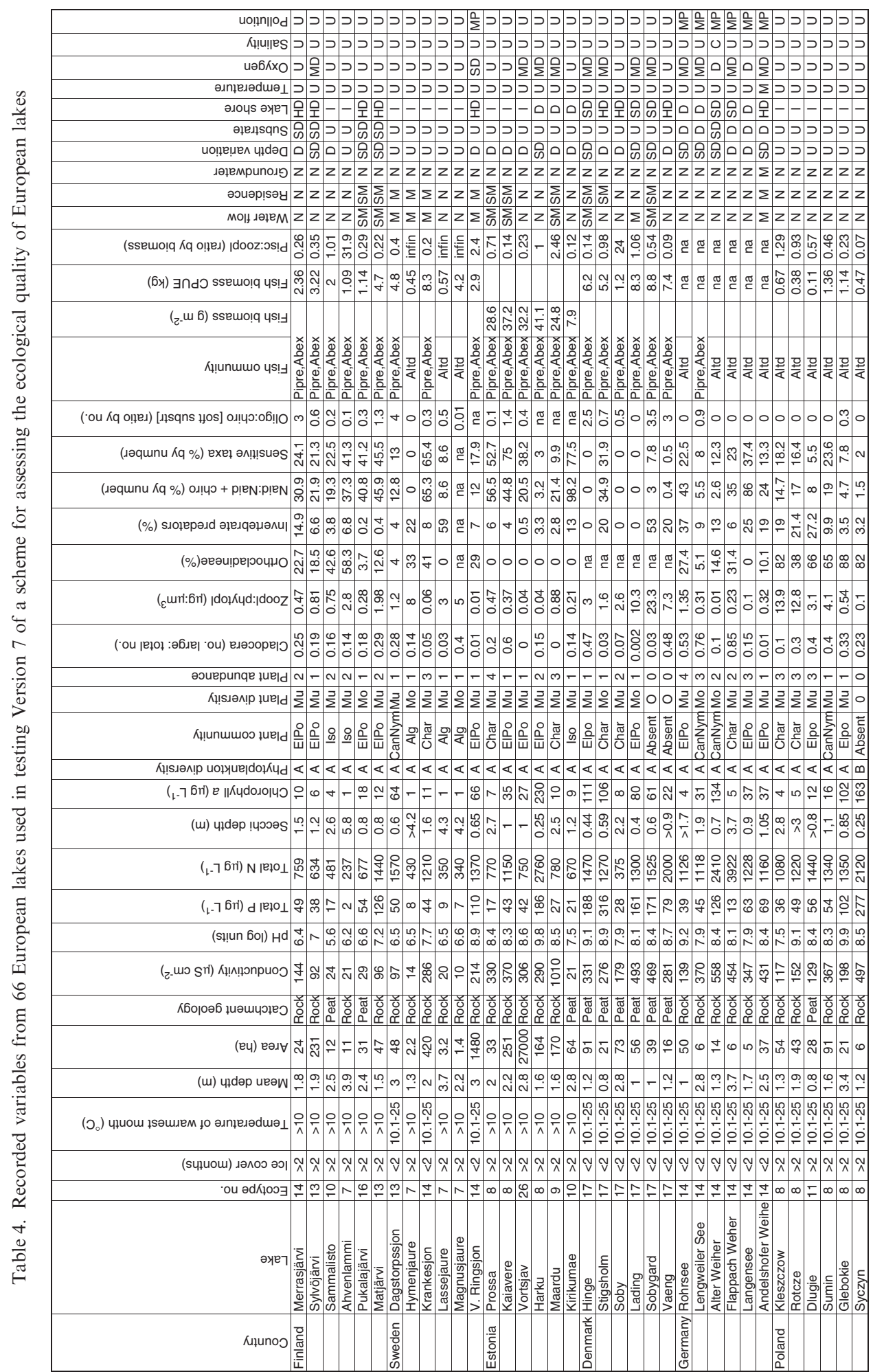




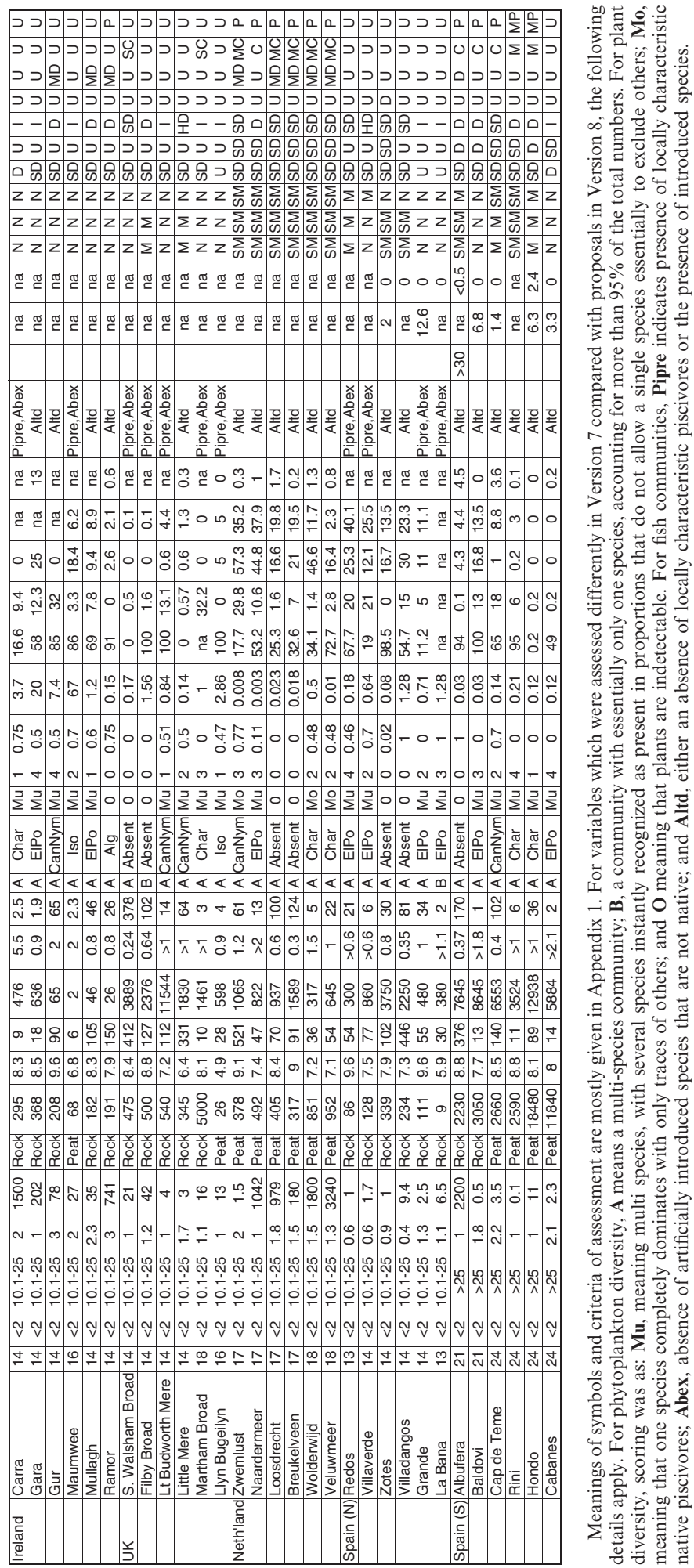


more than 60 people per 1000 lakes examined per year might be expected. Surveillance and restoration operations will keep at least this number of people employed subsequently. It should be remembered that this scheme is a minimalist one, its components being much less complicated than many procedures currently being examined by competent authorities. However, the time investment needed is likely to be substantially greater than that involved in current monitoring in some States.

Data obtained for the 66 European lakes are shown in Table 4. There were examples from 13 of the 48 possible ecotypes, with a dearth of large lakes. This reflects the prominence of small lakes in Europe as a whole. Among the smaller lakes there were examples from half the possible ecotypes. Assessments of ecological status have been made based on these data using Version 7 of the scheme. This differs in many details from Version 8 given in the Appendix, but not so greatly that most assessments would be substantially altered. In making assessments, the highest possible status was ascribed where the value of a variable would fit more than one category.

Table 5 shows correlations among numerical variables in the data in Table 4. It confirms that there is little redundancy in the measures used, for most are not significantly correlated. The exception is the group of variables linked through phytoplankton production and the results here are as expected. Total phosphorus is linked with chlorophyll and negatively with Secchi disc depth and plant abundance. Chlorophyll is positively correlated with $\mathrm{pH}$ and negatively with Secchi transparency. Plant abundance is related to Secchi transparency. Correlations between chemistry and invertebrate indicators are few and isolated, suggesting that these are measuring independent properties of the ecosystem.

Assessments of quality were made in several ways. One interpretation of the Directive is that to attain a given status, all variables must meet that standard (Environment Agency, 2002). Hence we have assessed the lakes on this criterion of $100 \%$ compliance (Table 6). This is undoubtedly unrealistic, because of high natural variability in most characteristics, but raises the issue of what proportion of individual variables must fall into a particular category or better for a given status to have been achieved. Logic suggests that this should not be lower than half, so this has been used as a criterion in Table 6 also. Half, however, is not a particularly stringent criterion, so assessments have also been included where $75 \%$ of the variables have to achieve a particular status or better for the lake to be given that status. In all cases we have calculated the

Table 5. Relationships among numerical variables obtained from 66 European lakes. Values are correlation coefficients

\begin{tabular}{|c|c|c|c|c|c|c|c|c|c|c|c|c|}
\hline & $\mathrm{TP}$ & $\mathrm{TN}$ & Secchi & Cphyll & $\begin{array}{l}\text { Plant } \\
\text { abund }\end{array}$ & $\begin{array}{c}\text { Zoopl } \\
\text { lge:total }\end{array}$ & $\begin{array}{l}\text { Zoopl: } \\
\text { phytop }\end{array}$ & $\begin{array}{c}\text { Orthocl } \\
(\%)\end{array}$ & $\begin{array}{c}\text { Predat } \\
(\%)\end{array}$ & $\begin{array}{c}\text { Naidids } \\
(\%)\end{array}$ & $\begin{array}{c}\text { Sensits } \\
(\%)\end{array}$ & $\begin{array}{l}\text { oligo: } \\
\text { chiro }\end{array}$ \\
\hline $\mathrm{pH}$ & ns & ns & $-0.35 *$ & $0.33 *$ & ns & ns & ns & ns & ns & ns & ns & ns \\
\hline $\mathrm{TP}$ & & & $-0.52 * * *$ & $0.63 * * *$ & $-0.35 * *$ & $0.26^{*}$ & ns & ns & ns & ns & ns & ns \\
\hline $\mathrm{TN}$ & & & $0.36 * *$ & ns & ns & ns & ns & ns & ns & ns & $-0.27 *$ & ns \\
\hline Secchi & & & & $-0.54 * * *$ & $0.32 *$ & ns & ns & ns & ns & ns & ns & ns \\
\hline Cphyll & & & & & $-0.41 * *$ & ns & ns & ns & ns & ns & $-0.27 *$ & ns \\
\hline Plant abund & & & & & & ns & ns & ns & ns & ns & ns & ns \\
\hline Zoopl lge: total & & & & & & & ns & ns & ns & ns & ns & ns \\
\hline Zoopl: phytop & & & & & & & & ns & ns & ns & ns & $0.49 * *$ \\
\hline Orthocl $(\%)$ & & & & & & & & & ns & ns & ns & ns \\
\hline Predat $(\%)$ & & & & & & & & & & ns & ns & ns \\
\hline Naidids $(\%)$ & & & & & & & & & & & $0.39 * *$ & ns \\
\hline Sensits $(\%)$ & & & & & & & & & & & ns & ns \\
\hline
\end{tabular}

$* p<0.05, * * p<0.01, * * * p<0.01$; ns, not significant. Abbreviations: TP, total phosphorus concentration; TN, total nitrogen concentration; Secchi, Secchi disc transparency; Cphyll, chlorophyll $a$ concentration; Plant abund, Plant abundance; Zoopl lge:total, ratio of numbers of large $(>0.5 \mathrm{~mm})$ Cladocera to total Cladocera; Orthocl $(\%)$, Orthocladiniiae as percentage of total chironomid numbers; Predat, predators as a percentage of total macroinvertebrates; Naidids, Naididae as a percentage of total numbers of chironomids plus Naididae; Sensits, percentage of sensitive taxa (Naididae, Ephemeroptera, Plecoptera, Trichoptera) of total number of macroinvertebrates; oligo:chiro, ratio of numbers of oligochaetes to numbers of chironomids in soft sediments. 
Table 6. Assessments of ecological status of 66 European lakes, based on three compliance levels and using three groupings of variables

\begin{tabular}{|c|c|c|c|c|c|c|c|c|c|c|}
\hline \multirow[b]{2}{*}{ Compliance level } & & \multicolumn{3}{|c|}{ Biological } & \multicolumn{3}{|c|}{$\begin{array}{c}\text { Biological } \\
\text { and related }\end{array}$} & \multicolumn{3}{|c|}{ All } \\
\hline & & $100 \%$ & $75 \%$ & $50 \%$ & $100 \%$ & $75 \%$ & $50 \%$ & $100 \%$ & $75 \%$ & $50 \%$ \\
\hline \multirow{6}{*}{ Finland } & Merrasjärvi & $\mathrm{P}$ & M & M & $\mathrm{P}$ & $\mathrm{P}$ & M & $\mathrm{P}$ & M & $\mathrm{H}$ \\
\hline & Sylvöjärvi & $\mathrm{P}$ & M & $\mathrm{H}$ & $\mathrm{P}$ & M & M & $\mathrm{P}$ & M & $\mathrm{H}$ \\
\hline & Sammalisto & $\mathrm{P}$ & M & $\mathrm{H}$ & $\mathrm{P}$ & G & $\mathrm{H}$ & $\mathrm{P}$ & $\mathrm{H}$ & $\mathrm{H}$ \\
\hline & Ahvenlammi & $\mathrm{P}$ & M & $\mathrm{H}$ & $\mathrm{P}$ & $\mathrm{H}$ & $\mathrm{H}$ & $\mathrm{P}$ & $\mathrm{H}$ & $\mathrm{H}$ \\
\hline & Pukalajärvi & $\mathrm{P}$ & $\mathrm{P}$ & M & $\mathrm{P}$ & $\mathrm{P}$ & M & $\mathrm{P}$ & $\mathrm{P}$ & M \\
\hline & Matjärvi & $\mathrm{P}$ & M & $\mathrm{H}$ & $\mathrm{P}$ & $\mathrm{M}$ & G & $\mathrm{P}$ & $\mathrm{P}$ & $\mathrm{G}$ \\
\hline \multirow[t]{6}{*}{ Sweden } & Dagstorpssjon & $\mathrm{P}$ & M & $\mathrm{H}$ & $\mathrm{P}$ & M & $\mathrm{H}$ & $\mathrm{P}$ & $\mathrm{M}$ & $\mathrm{H}$ \\
\hline & Hymenjaure & $\mathrm{P}$ & M & $\mathrm{H}$ & $\mathrm{P}$ & M & $\mathrm{H}$ & $\mathrm{P}$ & M & $\mathrm{H}$ \\
\hline & Krankesjon & $\mathrm{P}$ & $\mathrm{P}$ & M & $\mathrm{P}$ & $\mathrm{P}$ & $\mathrm{G}$ & $\mathrm{P}$ & M & $\mathrm{H}$ \\
\hline & Lassejaure & $\mathrm{P}$ & M & $\mathrm{H}$ & $\mathrm{P}$ & M & $\mathrm{H}$ & $\mathrm{P}$ & $\mathrm{H}$ & $\mathrm{H}$ \\
\hline & Magnusjaure & $\mathrm{P}$ & M & $\mathrm{H}$ & $\mathrm{P}$ & M & $\mathrm{H}$ & $\mathrm{P}$ & $\mathrm{H}$ & $\mathrm{H}$ \\
\hline & V. Ringsjon & $\mathrm{P}$ & $\mathrm{P}$ & M & $\mathrm{P}$ & $\mathrm{P}$ & M & $\mathrm{P}$ & $\mathrm{P}$ & M \\
\hline \multirow[t]{6}{*}{ Estonia } & Prossa & M & M & M & $\mathrm{P}$ & M & M & $\mathrm{P}$ & M & $\mathrm{H}$ \\
\hline & Kaiavere & $\mathrm{P}$ & M & M & $\mathrm{P}$ & $\mathrm{P}$ & G & $\mathrm{P}$ & $\mathrm{P}$ & $\mathrm{H}$ \\
\hline & Vortsjav & $\mathrm{P}$ & $\mathrm{P}$ & M & $\mathrm{P}$ & $\mathrm{P}$ & M & $\mathrm{P}$ & $\mathrm{M}$ & $\mathrm{H}$ \\
\hline & Harku & $\mathrm{P}$ & $\mathrm{P}$ & M & $\mathrm{P}$ & $\mathrm{P}$ & $\mathrm{M}$ & $\mathrm{P}$ & $\mathrm{P}$ & $\mathrm{G}$ \\
\hline & Maardu & $\mathrm{P}$ & M & $\mathrm{H}$ & $\mathrm{P}$ & M & $\mathrm{H}$ & $\mathrm{P}$ & M & $\mathrm{H}$ \\
\hline & Kirikumae & $\mathrm{P}$ & M & $\mathrm{H}$ & $\mathrm{P}$ & M & $\mathrm{H}$ & $\mathrm{P}$ & M & $\mathrm{H}$ \\
\hline \multirow[t]{6}{*}{ Denmark } & Hinge & $\mathrm{P}$ & $\mathrm{M}$ & $\mathrm{H}$ & $\mathrm{P}$ & $\mathrm{P}$ & M & B & $\mathrm{P}$ & $\mathrm{G}$ \\
\hline & Stigsholm & $\mathrm{P}$ & $\mathrm{M}$ & $\mathrm{H}$ & $\mathrm{P}$ & M & $\mathrm{H}$ & $\mathrm{P}$ & $\mathrm{M}$ & $\mathrm{H}$ \\
\hline & Soby & $\mathrm{P}$ & $\mathrm{H}$ & $\mathrm{H}$ & $\mathrm{P}$ & $\mathrm{H}$ & $\mathrm{H}$ & $\mathrm{P}$ & $\mathrm{H}$ & $\mathrm{H}$ \\
\hline & Lading & $\mathrm{P}$ & M & $\mathrm{H}$ & $\mathrm{P}$ & $P$ & $\mathrm{H}$ & $\mathrm{P}$ & $\mathrm{P}$ & $\mathrm{H}$ \\
\hline & Sobygard & $\mathrm{P}$ & $\mathrm{P}$ & $\mathrm{H}$ & $\mathrm{P}$ & $\mathrm{P}$ & M & $\mathrm{P}$ & $\mathrm{P}$ & G \\
\hline & Vaeng & $\mathrm{P}$ & $\mathrm{P}$ & M & $\mathrm{P}$ & $\mathrm{P}$ & M & $\mathrm{P}$ & M & $\mathrm{H}$ \\
\hline \multirow{6}{*}{ Germany } & Rohrsee & $\mathrm{M}$ & M & $\mathrm{H}$ & $\mathrm{P}$ & $\mathrm{M}$ & $\mathrm{H}$ & $\mathrm{P}$ & G & $\mathrm{H}$ \\
\hline & Lengenweiler See & $\mathrm{P}$ & M & M & $\mathrm{P}$ & M & M & $\mathrm{P}$ & $\mathrm{M}$ & G \\
\hline & Alter Weiher & $\mathrm{P}$ & $\mathrm{P}$ & M & $\mathrm{P}$ & $\mathrm{P}$ & M & B & $\mathrm{P}$ & $\mathrm{M}$ \\
\hline & Flappach Weiher & $\mathrm{P}$ & $\mathrm{H}$ & $\mathrm{H}$ & $\mathrm{P}$ & $\mathrm{H}$ & $\mathrm{H}$ & B & G & $\mathrm{H}$ \\
\hline & Langensee & $\mathrm{P}$ & $\mathrm{P}$ & M & $\mathrm{P}$ & $\mathrm{P}$ & M & $\mathrm{P}$ & M & G \\
\hline & Andeshofer Weiher & $\mathrm{P}$ & M & M & $\mathrm{P}$ & $\mathrm{P}$ & M & $\mathrm{P}$ & $\mathrm{M}$ & $\mathrm{M}$ \\
\hline \multirow[t]{6}{*}{ Poland } & Kleszczów & $\mathrm{P}$ & M & $\mathrm{H}$ & $\mathrm{P}$ & M & $\mathrm{H}$ & $\mathrm{P}$ & G & $\mathrm{H}$ \\
\hline & Rotcze & $\mathrm{P}$ & M & $\mathrm{H}$ & $\mathrm{P}$ & M & G & $\mathrm{P}$ & M & $\mathrm{H}$ \\
\hline & DLugie & $\mathrm{P}$ & M & $\mathrm{H}$ & $\mathrm{P}$ & M & $\mathrm{H}$ & $\mathrm{P}$ & $\mathrm{M}$ & $\mathrm{H}$ \\
\hline & Sumin & $\mathrm{P}$ & G & $\mathrm{H}$ & $\mathrm{P}$ & $\mathrm{M}$ & $\mathrm{H}$ & $\mathrm{P}$ & G & $\mathrm{H}$ \\
\hline & GKebokie & $\mathrm{P}$ & M & $\mathrm{H}$ & $\mathrm{P}$ & $\mathrm{P}$ & M & $\mathrm{P}$ & M & $\mathrm{H}$ \\
\hline & Syczýnskie & B & $\mathrm{P}$ & $\mathrm{P}$ & B & $\mathrm{P}$ & $\mathrm{P}$ & B & $\mathrm{P}$ & $\mathrm{H}$ \\
\hline \multirow[t]{6}{*}{ Ireland } & Carra & M & $\mathrm{H}$ & $\mathrm{H}$ & M & $\mathrm{H}$ & $\mathrm{H}$ & M & $\mathrm{H}$ & $\mathrm{H}$ \\
\hline & Gara & M & M & $\mathrm{H}$ & $\mathrm{P}$ & $\mathrm{M}$ & $\mathrm{H}$ & $\mathrm{P}$ & M & $\mathrm{H}$ \\
\hline & Gur & $\mathrm{P}$ & M & $\mathrm{H}$ & $\mathrm{P}$ & M & $\mathrm{H}$ & $\mathrm{P}$ & $\mathrm{M}$ & $\mathrm{H}$ \\
\hline & Maumwee & M & $\mathrm{H}$ & $\mathrm{H}$ & M & $\mathrm{H}$ & $\mathrm{H}$ & $\mathrm{P}$ & $\mathrm{H}$ & $\mathrm{H}$ \\
\hline & Mullagh & $\mathrm{P}$ & M & $\mathrm{H}$ & $\mathrm{P}$ & $\mathrm{M}$ & $\mathrm{H}$ & $\mathrm{P}$ & $\mathrm{M}$ & $\mathrm{H}$ \\
\hline & Ramor & $\mathrm{P}$ & $\mathrm{P}$ & M & $\mathrm{P}$ & $\mathrm{P}$ & M & $\mathrm{P}$ & M & $\mathrm{H}$ \\
\hline \multirow[t]{6}{*}{ UK } & S. Walsham Broad & $\mathrm{P}$ & $\mathrm{P}$ & M & $\mathrm{P}$ & $\mathrm{P}$ & $\mathrm{P}$ & B & $\mathrm{P}$ & $\mathrm{M}$ \\
\hline & Filby Broad & B & $\mathrm{P}$ & $\mathrm{P}$ & B & $\mathrm{P}$ & $\mathrm{P}$ & B & $\mathrm{P}$ & $\mathrm{M}$ \\
\hline & Lt. Budworth Mere & M & G & $\mathrm{H}$ & $\mathrm{P}$ & $\mathrm{M}$ & $\mathrm{H}$ & $\mathrm{P}$ & G & $\mathrm{H}$ \\
\hline & Little Mere & $\mathrm{P}$ & M & $\mathrm{H}$ & $\mathrm{P}$ & $\mathrm{P}$ & $\mathrm{H}$ & $\mathrm{P}$ & $\mathrm{M}$ & $\mathrm{H}$ \\
\hline & Martham Broad & $\mathrm{P}$ & $\mathrm{H}$ & $\mathrm{H}$ & $\mathrm{P}$ & $\mathrm{H}$ & $\mathrm{H}$ & $\mathrm{P}$ & $\mathrm{H}$ & $\mathrm{H}$ \\
\hline & Llyn Bugeilyn & M & $\mathrm{H}$ & $\mathrm{H}$ & $\mathrm{P}$ & G & $\mathrm{H}$ & $\mathrm{P}$ & $\mathrm{H}$ & $\mathrm{H}$ \\
\hline \multirow[t]{2}{*}{ Netherlands } & Zwemlust & $\mathrm{P}$ & $\mathrm{M}$ & M & $\mathrm{P}$ & $\mathrm{P}$ & M & B & $\mathrm{P}$ & $\mathrm{M}$ \\
\hline & Naardermeer & $\mathrm{P}$ & M & G & $\mathrm{P}$ & $\mathrm{P}$ & $\mathrm{G}$ & $\mathrm{P}$ & $\mathrm{P}$ & $\mathrm{G}$ \\
\hline
\end{tabular}


Table 6 (continued)

\begin{tabular}{llccccccccc}
\hline & & \multicolumn{3}{c}{ Biological } & \multicolumn{3}{c}{$\begin{array}{c}\text { Biological } \\
\text { and related }\end{array}$} \\
\hline & & & \multicolumn{3}{c}{ All } \\
\hline Compliance level & & $100 \%$ & $75 \%$ & $50 \%$ & $100 \%$ & $75 \%$ & $50 \%$ & $100 \%$ & $75 \%$ & $50 \%$ \\
\hline & Loosdrecht & $\mathrm{P}$ & $\mathrm{P}$ & $\mathrm{P}$ & $\mathrm{P}$ & $\mathrm{P}$ & $\mathrm{P}$ & $\mathrm{B}$ & $\mathrm{P}$ & $\mathrm{P}$ \\
& Breukelven & $\mathrm{P}$ & $\mathrm{P}$ & $\mathrm{P}$ & $\mathrm{P}$ & $\mathrm{P}$ & $\mathrm{P}$ & $\mathrm{B}$ & $\mathrm{P}$ & $\mathrm{P}$ \\
& Wolderwijd & $\mathrm{M}$ & $\mathrm{M}$ & $\mathrm{H}$ & $\mathrm{P}$ & $\mathrm{M}$ & $\mathrm{H}$ & $\mathrm{B}$ & $\mathrm{P}$ & $\mathrm{G}$ \\
Spain (N) & Veluwmeer & $\mathrm{P}$ & $\mathrm{M}$ & $\mathrm{H}$ & $\mathrm{P}$ & $\mathrm{M}$ & $\mathrm{H}$ & $\mathrm{B}$ & $\mathrm{P}$ & $\mathrm{M}$ \\
& Redos & $\mathrm{P}$ & $\mathrm{M}$ & $\mathrm{H}$ & $\mathrm{P}$ & $\mathrm{M}$ & $\mathrm{H}$ & $\mathrm{B}$ & $\mathrm{M}$ & $\mathrm{H}$ \\
& Villaverde & $\mathrm{M}$ & $\mathrm{M}$ & $\mathrm{H}$ & $\mathrm{P}$ & $\mathrm{M}$ & $\mathrm{H}$ & $\mathrm{P}$ & $\mathrm{M}$ & $\mathrm{H}$ \\
& Zotes & $\mathrm{P}$ & $\mathrm{P}$ & $\mathrm{M}$ & $\mathrm{P}$ & $\mathrm{P}$ & $\mathrm{P}$ & $\mathrm{B}$ & $\mathrm{P}$ & $\mathrm{P}$ \\
& Villadangos & $\mathrm{P}$ & $\mathrm{P}$ & $\mathrm{M}$ & $\mathrm{P}$ & $\mathrm{P}$ & $\mathrm{M}$ & $\mathrm{B}$ & $\mathrm{P}$ & $\mathrm{M}$ \\
& Grande & $\mathrm{P}$ & $\mathrm{M}$ & $\mathrm{M}$ & $\mathrm{P}$ & $\mathrm{M}$ & $\mathrm{M}$ & $\mathrm{P}$ & $\mathrm{M}$ & $\mathrm{H}$ \\
& La Bana & $\mathrm{B}$ & $\mathrm{M}$ & $\mathrm{M}$ & $\mathrm{B}$ & $\mathrm{M}$ & $\mathrm{G}$ & $\mathrm{B}$ & $\mathrm{M}$ & $\mathrm{H}$ \\
& Albufera & $\mathrm{P}$ & $\mathrm{P}$ & $\mathrm{M}$ & $\mathrm{P}$ & $\mathrm{P}$ & $\mathrm{M}$ & $\mathrm{P}$ & $\mathrm{P}$ & $\mathrm{M}$ \\
& Baldovi & $\mathrm{P}$ & $\mathrm{P}$ & $\mathrm{G}$ & $\mathrm{P}$ & $\mathrm{P}$ & $\mathrm{G}$ & $\mathrm{P}$ & $\mathrm{M}$ & $\mathrm{H}$ \\
& Cap de Terme & $\mathrm{P}$ & $\mathrm{P}$ & $\mathrm{H}$ & $\mathrm{P}$ & $\mathrm{P}$ & $\mathrm{M}$ & $\mathrm{B}$ & $\mathrm{P}$ & $\mathrm{M}$ \\
& Rini & $\mathrm{M}$ & $\mathrm{M}$ & $\mathrm{H}$ & $\mathrm{P}$ & $\mathrm{M}$ & $\mathrm{H}$ & $\mathrm{P}$ & $\mathrm{P}$ & $\mathrm{G}$ \\
& Hondo & $\mathrm{P}$ & $\mathrm{P}$ & $\mathrm{H}$ & $\mathrm{P}$ & $\mathrm{P}$ & $\mathrm{G}$ & $\mathrm{P}$ & $\mathrm{M}$ & $\mathrm{G}$ \\
& Cabanes & $\mathrm{P}$ & $\mathrm{P}$ & $\mathrm{M}$ & $\mathrm{P}$ & $\mathrm{P}$ & $\mathrm{M}$ & $\mathrm{P}$ & $\mathrm{M}$ & $\mathrm{H}$ \\
\hline
\end{tabular}

At the $100 \%$ compliance level, all variables had to meet the requirements stipulated for a particular status class or a higher one. For $75 \%$ compliance at least three quarters had to meet the requirements for a particular class or a higher class and similarly for the $50 \%$ compliance level. Biological variables included chlorophyll $a$, phytoplankton community, and all variables concerned with plants, zooplankton, macroinvertebrates and fish, where available. Biologically related variables included $\mathrm{pH}$, total $\mathrm{P}$, total $\mathrm{N}$, Secchi disc transparency and structure of the lake shore. H, high; G, good; M, moderate; P, poor; B, bad.

assessment based on the total number of variables for which data were available. In many cases fish biomass data and piscivore to zooplanktivore ratios were not available.

The Directive also indicates that water bodies should be classified according to ecological status and physical and chemical status and that the final classification shall be determined by the lesser of the two. Assessments here are based on strict ecological status using only biological variables and also on all the variables combined. Assessments are also made on a compromise group which included the strictly biological variables (chlorophyll, macrophytes, phytoplankton, zooplankton, macroinvertebrates, fish) together with those that are so closely related as to be ecologically inseparable ( $\mathrm{pH}, \mathrm{TP}, \mathrm{TN}$, Secchi depth, shoreline structure). Thus Table 6 includes nine possible assessments for each lake. These data are summarized as frequency distributions in Table 7. The distributions can be compared with the expected distribution of around one third each of the lakes in each of the groups high/good, moderate and poor/bad. Prior expectations were for $23 \mathrm{high} / \mathrm{good}, 21$ moderate and 22 poor/bad lakes, which is very close to a 1:1:1 ratio.

Using a criterion of $100 \%$ compliance among all variables, no lakes would be classed as high or good, rather few as moderate and most as poor or bad. Clearly this deviates markedly from expectation (Chi squared test for ratio of high/good : moderate : poor/bad, $\chi^{2}=17.8, \mathrm{df}=1, p<0.01$ ). Equally, using $50 \%$ compliance, a very high proportion emerges as high/good and many fewer as moderate or poor/bad. This is equally deviant $\left(\chi^{2}=13.7\right.$, $\left.\mathrm{df}=1, p<0.01\right)$. A closer fit $\left(\chi^{2}=4.0, d f=1, \mathrm{~ns}\right)$ is realized with $75 \%$ compliance, though with fewer than notionally expected in the high/good categories. Few of the lakes could truly be said to be at high status based on the Directive's very stringent definition, yet $13.6 \%$ fell into this category at the $75 \%$ compliance level. This level therefore represents perhaps a less than stringent choice, and operationally perhaps a level of $80 \%$ compliance might be more appropriate. 
Table 7. Frequency distribution of ecological status classes among European lakes, dependent on percentage compliance and different groups of variables. Data are summarized from Table 6

\begin{tabular}{|c|c|c|c|c|c|c|c|c|c|}
\hline \multirow[t]{2}{*}{ Compliance level } & \multicolumn{3}{|c|}{$100 \%$} & \multicolumn{3}{|c|}{$75 \%$} & \multicolumn{3}{|c|}{$50 \%$} \\
\hline & $\mathrm{H} / \mathrm{G}$ & $\mathrm{M}$ & $\mathrm{P} / \mathrm{B}$ & $\mathrm{H} / \mathrm{G}$ & M & $\mathrm{P} / \mathrm{B}$ & $\mathrm{H} / \mathrm{G}$ & M & $\mathrm{P} / \mathrm{B}$ \\
\hline Biological & 0 & 15.4 & 84.6 & 12.1 & 54.5 & 33.3 & 60.6 & 33.3 & 6.1 \\
\hline Biological + related & 0 & 3.0 & 96.9 & 12.1 & 40.9 & 47 & 58.5 & 33 & 7.7 \\
\hline All variables & 0 & 1.5 & 98.4 & 19.7 & 43.9 & 33.3 & 78.7 & 16.7 & 4.5 \\
\hline Expected & 34.9 & 31.9 & 33.2 & 34.9 & 33.3 & 33.2 & 34.9 & 31.9 & 33.2 \\
\hline
\end{tabular}

Chi squared tests reported in the text were carried out on absolute numbers but values are given as percentages of the total number of lakes for comparability.

Use of biological variables alone was not more stringent than using all variables. At $100 \%$ compliance, using all variables downgraded lakes that had fallen into the moderate class to poor, but at $75 \%$ compliance a few were upgraded by using all variables and there was a closer comparison with the notional distribution. In general, the more variables that are incorporated, the more accurate the assessment because there is an inherent high probability that, on a single sampling occasion, almost any one will be deviant, as instanced by the classification of almost all of the sample as poor or bad if there is insistence on $100 \%$ compliance.

\section{DISCUSSION}

No scheme will ever be perfect. Absolute validity is not possible where reference sites no longer exist and where degrees of quality can only rest on arbitrary, if informed, judgements. The intentions of the Directive are sometimes confounded by over-prescription of details, and these prescriptions have not always been informed by current ecological understanding or practical familiarity with the ecosystems themselves. Nonetheless, it has been possible to develop a scheme that satisfies a group of independent experts, closely familiar with the ecosystems concerned and in doing so to reveal and overcome some of the operational difficulties. Specifying boundaries for classes is not easy when the ecosystem may be simultaneously influenced by several impacts and generates its own internal dynamics.

Some difficulties remain. Annex V of the Directive talks of 'type-specific communities' and 'major taxonomic groups of the type' and 'ratio of disturbance-sensitive to insensitive taxa'. In ECOFRAME, taxa have not been specified as closely as these terms might imply but these terms have been interpreted liberally in the use of ratios and community types. The drafters of Annex V seem to have had a deterministic view of ecosystems: that given the imposition of particular conditions in a particular place, there is a sole and predictable outcome in terms of species composition that can be simply measured and inserted into ratios such as the 'environmental quality ratio', by which the shortfall from high status is supposed to be expressible. Ecosystems are not so simple, however. They never conform to single formulae and there is a fundamental clash between the prescriptions of the Directive and the material to which it applies.

One problem will be the determination of how statistically reliable the estimates of status are. What is the chance of an error in ascribing a particular status? Extensive sampling will show that all of the variables used here to measure quality will individually have wide ranges in a particular system. This is the existing experience of ecologists. Calculation of environmental quality ratios for single variables will thus be subject to enormous uncertainty. For example, the chlorophyll $a$ concentration in a given lake may change from $30 \mu \mathrm{g} \mathrm{L}^{-1}$ in May when the spring diatom peak occurs, to $3 \mu \mathrm{g} \mathrm{L}^{-1}$, a week later, when the diatoms become limited by nitrogen or silica. The development of large numbers of daphnids in June, before the young-ofthe-year fish have grown large enough to feed on them, may result in a very low chlorophyll clear-water 
phase which is replaced a week later by a major peak as the young fish decimate the zooplankton. In a single lake during the summer, therefore, the entire range specified for different statuses can be met.

Calculation of environmental quality ratios is also impossible where qualitative features such as the nature of the plant community are concerned, yet these are among the most important measures of ecological quality. The assumptions of Annex V of the Directive seem to be that impacts on the systems are reflected in a simple proportional change in a constant set of taxonomic components. This is clearly never the case; the system changes to reflect the impact, acquiring new species by colonization and losing some by local extinction.

Collectively, however, the use of 28 variables will give a much more reliable way of expressing environmental quality ratios in terms of the number of variables attributable to particular classes. It is not possible to say how reliable without wider-scale testing, but multiple sampling on single sites, and application of the assessment on each occasion, will be able to show probabilities of obtaining particular classes. Data on multiple sampling of pond mesocosms (McKee et al., 2002) indicates that such an exercise would show very high reliability if based on the entire suite of variables or a substantial majority of them.

An alternative approach is to regard the percentage of variables falling into a particular status class as a measure of reliability that that status is the true assessment, or alternatively the number of variables falling into a given or higher status. This latter is the approach taken in Tables 6 and 7. Expectations of $100 \%$ compliance or $50 \%$ compliance are unreliable, but $75 \%$ compliance gave a pattern that was not significantly different from that expected from the choice of sites. Use of percentage compliance thus allows an assessment of the risk of misclassification to be made. This might be done by regarding the percentage of variables falling into a particular class or a higher one as the probability of the lake falling into that class or a higher one. More sophisticated assessments could give different weightings to some variables compared with others.

A further approach might be to evaluate the amalgamated percentage compliance across a set of lakes in a given ecotype in a particular River Basin District (the management unit for the Water Framework Directive). This would minimize the risk of misclassification of a particular water body owing to stochastic factors but assumes that all examples of an ecotype in the District are subject to similar impacts. This may often be the case, but not always.

\section{Extension of the scheme to all lakes}

The Water Framework Directive ultimately has to be applied to all lakes, not just shallow ones. There are two obvious differences between shallow lakes as discussed here and deeper lakes. First, the predominance of bottom primary production is lost to predominance by phytoplankton in a deeper lake simply as a

function of availability of the two sorts of habitat. Second, the water mass will be more likely to stratify, with the possibility that the chemical nature of the water in the hypolimnion will change markedly from that in the epilimnion. There is a common presumption that the degree of deoxygenation of the hypolimnion will reflect ecological quality. A reduction from that in the pristine state will certainly indicate this, but in absolute terms a deoxygenated hypolimnion may be pristine if the volume of the hypolimnion is small in relation to that of the epilimnion. It is a lake-specific feature and thus cannot be built into a quality scheme except in the way that ECOFRAME deals with other lake-specific features (see Appendix 1).

In other respects a deep lake will behave much as a shallow one, though the seasonal dynamics of many variables will differ owing to the effects of stratification. The scheme developed reflects the ecology of all lakes. In the interests of usability, two possibilities might be suggested. The simplest is that depth is ignored as a variable in the typology and that samples be taken from epilimnion water and sediments where the lake stratifies, and that the scheme simply be applied to all lakes in the next stage of operational testing. Minor adjustment would be needed to the stipulations for macrophyte coverage to allow for the fact that much of a deep lake might be unavailable for macrophyte colonization. 
However, Annex II of the Directive implies that depth is a mandatory component of typologies. Thus we suggest a simple creation of two depth categories, $<3 \mathrm{~m}$ and $>3 \mathrm{~m}$ mean depth, and a simple replication of the 48 ecotypes of the present shallow lakes scheme with the characteristics of ecological quality unchanged, except for the proviso concerning macrophyte coverage discussed above.

\section{A final observation}

During the workshop discussions of this project, one of us remarked that from a single visit to a lake, an overview of its catchment, knowledge of its $\mathrm{pH}$ and Secchi disc transparency, and a brief examination of its macrophytes, an experienced limnologist could easily distinguish high/good from moderate from poor/bad status. It is the tragedy of our time, perhaps of all times, that we must set up expensive and elaborate measures to do what, with experience, and consensus within society as to its environmental goals, could be done much more easily.

\section{ACKNOWLEDGEMENTS}

This work was supported by a Framework 5 contract from the European Commission (ECOFRAME, Contract EVK1-CT1999-00039). LAH was also supported from Swedish MISTRA funds through the VASTRA programme, and EJ and JPJ by the Danish Nature and Forest Agency. We are grateful for very helpful editorial and referee comments made by Dr P. Boon and Dr C. Duigan.

\section{REFERENCES}

Armitage PD, Cranston PS, Pinder, LCV (eds) 1995. The Chironomidae. Biology and Ecology of Non-Biting Midges. Chapman and Hall: London.

Bales M, Moss B, Phillips G, Irvine K, Snook D. 1993. The changing ecosystem of a shallow, brackish lake, Hickling Broad, Norfolk, UK. II. Long-term trends in water chemistry and ecology and their implications for restoration of the lake. Freshwater Biology 29: 141-166.

Bazzanti M, Seminara M. 1986. Profundal macrobenthos structure as a measure of long-term environmental stress in a polluted lake. Water, Air and Soil Pollution 33: 435-442.

Bennion H, Juggins S, Anderson NJ. 1996. Predicting epilimnetic phosphorus concentrations using an improved diatom-based transfer function and its application to lake eutrophication management. Environmental Science and Technology 30: 2004-2007.

Bennion H, Wunsam S, Schmidt R. 1995. The validation of diatom-phosphorus transfer functions: an example from Mondsee, Austria. Freshwater Biology 34: 271-283.

Berg K. 1938. Studies on the bottom animals of Esrom Lake. Danske Videnskabers Selskab Skrift 7:1-255.

Blindow I. 1992. Decline of charophytes during eutrophication: comparison with angiosperms. Freshwater Biology 28: $1-14$.

Boon PJ. 2000. The development of integrated methods for assessing river conservation value. Hydrobiologia 422: 413-428.

Brinkhurst RO. 1974. The Benthos of Lakes. Macmillan: London.

Brinkhurst RO, Cook DG (eds). 1980. Aquatic Oligochaete Biology. Plenum: New York.

Cahn AR. 1929. The effect of carp on a small lake: the carp as a dominant. Ecology 10: 271-274.

Chandler JR. 1970. A biological approach to water quality management. Water Pollution Control 69: 415-422.

Charlson RJ, Rodhe H. 1982. Factors controlling the acidity of natural rainwaters. Nature 295: 683-685.

Davies BR, Thoms M, Meador M. 1992. An assessment of the ecological impacts of inter-basin transfers, and their threats to river basin integrity and conservation. Aquatic Conservation: Marine and Freshwater Ecosystems 2: $325-350$.

Diehl S, Kornijów R. 1998. The influence of macrophytes on trophic interactions among fish and macroinvertebrates. In The Structuring Role of Submerged Macrophytes in Lakes, Jeppesen E, Søndergaard M, Søndergaard M, Christoffersen K. (eds). Springer Verlag: New York; 24-46. 
Dillon PJ. 1975. The application of the phosphorus-loading concept to eutrophication research. Environment Canada Science Series 46, Burlington: Ontario.

Environment Agency. 2002. The Water Framework Directive. Guiding Principles on the Technical Requirements. Environment Agency: Bristol.

Hansson L-A, Annadotter H, Bergman E, Hamrin SF, Jeppesen E, Kairesalo T, Luokkanen E, Nilsson PA, Søndergaard M, Strand J. 1998. Biomanipulation as an application of food-chain theory: constraints, synthesis and recommendations for temperate lakes. Ecosystems 1: 558-574.

Holdway PA, Watson RA, Moss B. 1978. Aspects of the ecology of Prymnesium parvum (Haptophyta) and water chemistry in the Norfolk Broads, England. Freshwater Biology 8: 295-311.

Hornung M. 1984. The impact of upland pasture improvement on solute outputs in surface waters. In Agriculture and the Environment, Jenkins D (ed.). Institute of Terrestrial Ecology: Cambridge; 150-155.

Hurlbert SH, Zedler J, Fairbanks D. 1971. Ecosystem alteration by mosquito fish (Gambusia affinis) predation. Science 175: $639-641$.

Hynes HBN. 1970. The Biology of Polluted Waters. Liverpool University Press: Liverpool.

Irvine K, Moss B, Balls HR. 1989. The loss of submerged plants with eutrophication. II Relationships between fish and zooplankton in a set of experimental ponds, and conclusions. Freshwater Biology 22: 89-107.

Jensen JP, Jeppesen E, Olrik K, Kristensen P. 1994. Impact of nutrients and physical factors on the shift from cyanobacterial to chlorophyte dominance in shallow Danish lakes. Canadian Journal of Fisheries and Aquatic Sciences 51: $1692-1699$.

Jeppesen E, Leavitt P, De Meester L, Jensen JP. 2001a. Functional ecology and palaeolimnology: using cladoceran remains to reconstruct anthropogenic impact. Trends in Ecology and Evolution 19: 191-198.

Jeppesen E, Jensen JP, Søndergaard M, Lauridsen T, Landkildehus F. 2001b. Trophic structure, species richness and biodiversity in Danish lakes: changes along a phosphorus gradient. Freshwater Biology 45: 201-218.

Jeppesen E, Jensen JP, Søndergaard M, Lauridsen T, Pedersen LJ, Jensen L. 1997. Top-down control in freshwater lakes: the role of nutrient state, submerged macrophytes and water depth. Hydrobiologia 342/3: $151-164$.

Jeppesen E, Madsen, EA, Jensen, JP, Anderson NJ. 1996. Reconstructing the past density of planktivorous fish and trophic structure from sedimentatry zooplankton fossils: a surface sediment calibration data set from shallow lakes. Freshwater Biology 36: 115-127.

Jeppesen E, Søndergaard M, Kronvang B, Jensen JP, Svendsen LM, Lauridsen TL. 1998. Lake and catchment management in Denmark. Hydrobiologia 395/396: 419-432.

Jeppesen E, Søndergaard M, Mortensen E, Kristensen P, Riemann B, Jensen HJ, Müller JP, Sortkjér O, Jensen JP, Christoffersen K, Bosselmann S, Dall E. 1990. Fish manipulation as a lake restoration tool in shallow, eutrophic temperate lakes 1: cross-analysis of three Danish case studies. Hydrobiologia 200/201: 205-218.

Jeppesen E, Søndergaard M, Søndergaard M, Christoffersen K (eds). 1998. The Structuring Role of Submerged Macrophytes in Lakes. Ecological Studies, vol 131, Springer Verlag: New York.

Johnes PJ. 1996. Evaluation and management of the impact of land use change on the nitrogen and phosphorus load delivered to surface waters: the export coefficient modelling approach. Journal of Hydrology 183: 323-349.

Johnes PJ, Moss B, Phillips GL. 1996. The determination of water quality by land use, livestock numbers and population data - testing of a model for use in conservation and water quality management. Freshwater Biology 36: 451-473.

Johnson R, Wiederholm K. 1989. Classification and ordination of profundal macroinvertebrate communities in nutrient poor, oligo-mesohumic lakes in relation to environmental data. Freshwater Biology 21: 375-386.

Kajak Z, Bretschko G, Schiemer F, Leveque C. 1980. Zoobenthos. In The Functioning of Freshwater Ecosystems, Le Cren ED, Lowe-McConnell RH (eds). Cambridge University Press: Cambridge; 285-307.

Kristensen P, Hansen HO. 1994. European Rivers and Lakes. Assessment of their Environmental State. EEA Environmental Monographs, vol 1. European Environment Agency: Copenhagen.

Kornijów R, Kairesalo T. 1994. A simple apparatus for sampling epiphytic communities associated with emergent macrophytes. Hydrobiologia 294: 141-143.

Lazzaro X. 1997. Do the trophic cascade hypothesis and classical biomanipulation approaches apply to tropical lakes and reservoirs? Verhandlungen der Internationalen Vereinigung für theoretische und angewande Limnologie 26: 719-730.

Lazzaro X, Drenner RW, Stein R.A, Smith JD. 1992. Planktivores and plankton dynamics - effects of fish biomass and planktivore type. Canadian Journal of Fisheries and Aquatic Sciences 49: 1466-1473.

Learner MA, Lochhead G, Hughes BD. 1978. A review of the biology of British Naididae (Oligochaeta) with emphasis on the lotic environment. Freshwater Biology 8: 357-375. 
Maberley SC, Spence DHN. 1983. Photosynthetic inorganic carbon use by freshwater plants. Journal of Ecology 71 : 705-724.

Macan TT 1963. Freshwater Ecology. Longman: London.

McCauley E, Kalff J. 1981. Empirical relationships between phytoplankton and zooplankton biomass in lakes. Canadian Journal of Fisheries and Aquatic Sciences 38: 458-463.

McGowan S, Britton G, Haworth E, Moss B. 1999. Ancient blue-green blooms. Limnology \& Oceanography 44: 436-439.

McKee D, Atkinson D, Collings S, Eaton J, Harvey I, Heyes T, Hatton K, Wilson D, Moss B. (2002) Macrozooplankter responses to simulated climate warming in experimental freshwater microcosms. Freshwater Biology 47: $1557-1570$.

Madsen TV, Sand-Jensen K. 1991. Photosynthetic carbon assimilation in aquatic macrophytes. Aquatic Botany 41: $5-40$.

Makarewicz JC, Likens GE. 1975. Niche analysis of a zooplankton community. Science 190: 1000-1002.

May RM. 1977. Thresholds and breakpoints in ecosystems with a multiplicity of stable states. Nature 269: 471-477.

Moss B. 1999. From algal culture to ecosystem, from information to culture. European Phycological Journal 34: 193-204.

Moss B, Kornijow R, Measey GJ. 1998. The effects of nymphaeid (Nuphar lutea L.) density and predation by perch (Perca fluviatilis L.) on the zooplankton communities in a shallow lake. Freshwater Biology 39: 689-697.

Moss B, Johnes PJ, Phillips GL 1997. New approaches to monitoring and classifying standing waters. In Freshwater Quality: Defining the Indefinable?, Boon PJ, Howell DL (ed.). The Stationery Office: Edinburgh; 118-133.

Moss B, McGowan S, Carvalho L. 1994. Determination of phytoplankton crops by top-down and bottom-up mechanisms in a group of English lakes, the West Midland meres. Limnology and Oceanography 39: 1020-1029.

Moss B, Madgwick J, Phillips G. 1996. A Guide to the Restoration of Nutrient-Enriched Shallow Lakes. Environment Agency, Broads Authority \& European Union Life Programme: Norwich.

Organisation for Economic Co-operation and Development. 1982. Eutrophication of Waters: Monitoring, Assessment and Control. OECD: Paris.

Palmer MA, Bell SL, Butterfield C. 1992. A botanical classification of standing waters in Britain: applications for conservation and monitoring. Aquatic Conservation: Marine and Freshwater Ecosystems 2: 125-143.

Pennington W. 1984. Long-term natural acidification of upland sites in Cumbria: evidence from post-glacial lake sediments. Annual Reports of the Freshwater Biological Association 52: 28-46.

Pimental D, McNair S, Janecka J, Wightman J, Simmonds C, O'Connell C, Wong E, Russel L, Zern J, Aquino T, Tsomondo T. 2001. Economic and environmental threats of alien plant, animal, and microbe invasions. Agricultural Ecosystems and Environment 84: 1-20.

Pollard P and Huxham M. 1998. The European Water Framework Directive: a new era in the management of aquatic ecosystem health? Aquatic Conservation: Marine and Freshwater Ecosystems 8: 773-792.

Raven PJ, Fox P, Everard M, Holmes NTH, Dawson FH, 1997. River Habitat Survey: a new system for classifying rivers according to their habitat quality. In Freshwater Quality: Defining the Indefinable?, Boon PJ, Howell DL (eds). The Stationery Office: Edinburgh; 215-234.

Rawson DS. 1956. Algal indicators of trophic lake types. Limnology \& Oceanography 1: 18-25.

Reynolds CS. 1984. The Ecology of Freshwater Phytoplankton. Cambridge University Press: Cambridge.

Reynolds CS. 1987. The response of phytoplankton communities to changing lake environments. Schweizerische Zeitschrift der Hydrologie 49: 220-236.

Reynolds CS. 2002. On the interannual variability in phytoplankton production in freshwaters. In Phytoplankton Productivity: Carbon Assimilation in Marine and Freshwater Ecosystems, Williams PJ Le B, Thomas DN, Reynolds CS (eds). Blackwell Science: Oxford; 187-221.

Saether OA. 1979. Chironomid communities as water quality indicators. Holarctic Ecology 2: 65-74.

Sayer C. 2001. Problems with diatom-total phosphorus transfer functions: examples from a shallow English lake. Freshwater Biology 46: 743-758.

Scheffer, M. (1998) Ecology of Shallow Lakes. Chapman \& Hall: London.

Scheffer M, Hosper SH, Meijer ML, Moss B, Jeppesen E. 1993. Alternative equilibria in shallow lakes. Trends in Ecology and Evolution 8: 275-279.

Schindler DW. 1978. Factors regulating phytoplankton production and standing crop in the world's freshwaters. Limnology \& Oceanography 23: 478-86.

Seddon B. 1972. Aquatic macrophytes as limnological indicators. Freshwater Biology 2: 107-130.

Sommaruga-Wögrath S, Koinig KA, Schmidt R, Sommaruga R, Tessadri R, Psenner R. 1997. Temperature effects on the acidity of remote alpine lakes. Nature 387: 64-67. 
ter Braak CJF, van Dam H. 1989. Inferring pH from diatoms: a comparison of old and new calibration methods. Hydrobiologia 178: 209-223.

Uzunov JI. 1982. Dissolved oxygen and saprobity as factors for the distribution of aquatic oligochaetes in rivers. Hydrobiology (Sofia) 16: 20-30.

Vallentyne JR. 1969. Sedimentary organic matter and palaeolimnology. Mitteilungen der internationalen Vereinigung für theoretische und angewande Limnologie 17: 104-110.

Van Donk E, Gulati RD. 1995. Transition of a lake to turbid state six years after biomanipulation: mechanisms and pathways. Water Science \& Technology 32: 197-206.

Vollenweider R. 1968. Scientific fundamentals of the eutrophication of lakes and flowing waters, with particular reference to nitrogen and phosphorus as factors in eutrophication. Technical Report Da 5/SC/68.27, OECD: Paris.

Wiederholm T. 1980. Use of benthos in lake monitoring. Journal of the Water Pollution Control Federation 52: 537-547.

Wright JF, Sutcliffe DW, Furse MT. 2000. Assessing the Biological Quality of Fresh Waters. Freshwater Biological Association: Ambleside.

\section{APPENDIX 1. METHODS AND CRITERIA FOR DETERMINING VARIABLES USED IN THE ECOFRAME VERSION 8 SCHEME FOR THE ASSESSMENT OF ECOLOGICAL STATUS IN SHALLOW LAKES}

\section{Typology}

The typology comprises 48 ecotypes based on:

Four climatic regions (cold (more than 2 months of ice cover, mean temperature of warmest month $<10^{\circ} \mathrm{C}$; $\operatorname{cool}(>2$ mo, $\left.>10^{\circ} \mathrm{C}\right)$; temperate $\left(<2 \mathrm{mo},>10<25^{\circ} \mathrm{C}\right)$; warm $\left(<2 \mathrm{mo},>25^{\circ} \mathrm{C}\right)$

Two lake area categories $\left(<100 \mathrm{~km}^{2} ;>100 \mathrm{~km}^{2}\right)$

Two geological categories (more than half of catchment rock-based; more than half of catchment peat-based)

Three water conductivities $\left(<100 \mu \mathrm{S} \mathrm{cm}^{-2} ; 101-800 \mu \mathrm{S} \mathrm{cm}^{-2} ;>801 \mu \mathrm{S} \mathrm{cm}^{-2}\right)$

\section{Methods for determining variables in the scheme and categories used}

(a) Water chemistry, chlorophyll $\boldsymbol{a}$ and Secchi disc depth. Samples should be taken offshore in summer to early autumn for biological variables. A sub-sample should be filtered for chlorophyll $a$ analysis within a few hours. Conductivity and $\mathrm{pH}$ should be determined in the field. Samples may be preserved for subsequent total P and total $\mathrm{N}$ analyses. Methods should be the standard methods normally used by competent authorities.

(b) Phytoplankton and zooplankton. Samples should be taken from the whole water column using a tube sampler. A sub-sample for phytoplankton should be preserved in Lugol's iodine for subsequent scanning under a compound microscope. Designations are A, several to many species present, and, if only one, absence of obvious surface aggregations of algae and of dominance in the sample $(>95 \%)$ of colonial or filamentous Cyanobacteria or Chlorococcales; B, as A but surface aggregations of Cyanobacteria noted or reported intermittently; C, sample dominated by filamentous or colonial Cyanobacteria, blooms obvious or reported frequently.

A sample of at least $10 \mathrm{~L}$ of water, pooled from several locations should be sieved through a $50 \mu \mathrm{m}$ mesh and the zooplankton preserved in ethanol. Subsamples of Crustacea should be identified to genus level and counted so as to give estimates of number $\mathrm{L}^{-1}$. Cladoceran counts should be classified as large (Daphnia, Leptodora, Polyphemus, Simocephalus, Sida, Diaphanosoma, Holopedium, Eurycercus) or small species (all others). Some Ceriodaphnia species are large $(>0.5 \mathrm{~mm})$ in which case they should be counted as 'large'. Counts of all Crustacea should be converted to dry biomass using compilations of data from literature or locally derived. Great precision is unnecessary.

(c) Plants and phytobenthos. The community over about $10 \%$ of the lake area should be scanned and recorded in one of the categories described below. The number of species of submerged and floating leaved vascular plants should be recorded and any invasive exotics noted. Abundance should be recorded as noted below following sampling with a stiff pronged grapnel or double headed rake.

Plant community

Alg: Low biomass, rocky communities, with aquatic mosses, filamentous desmids and Zygnematales forming small flocs, macroscopic red algae and sometimes the plum-like colonies of cyanophytes like Aphanocapsa and Nostoc. There 
may also be isolated plants of the isoetid group or, in more base-rich waters, of charophytes and mosses. The appearance will be of low abundance of small plants, though discrete beds may occur in sheltered areas.

Iso: Communities of greater abundance in softwater lakes with extensive sediment deposits, though still of small species, not growing up to the surface. These communities will be dominated by isoetids (Isoetes, Lobelia, Littorella) which have waxy cuticles and derive much of their carbon dioxide from the sediments through their root systems. Mosses may also be present.

Char: Communities of greater abundance in more base-rich waters with extensive sediment deposits, though still of small species generally not growing up to the water surface and dominated by charophytes, with vascular plant species. The latter may be abundant but generally not more so than the charophytes.

Sphag: Communities dominated by Sphagnum, occurring in extensive swards (as opposed to occasional patches), often with the acid-tolerant rush Juncus bulbosus.

EIPo: Communities of elodeids and pondweeds, rooted in sediment and often abundant though with several species present, often including nymphaeids and some aggressive charophytes. These plants may grow to the surface and form very dense beds.

CanNym: Extensive communities of nymphaeids and/or canopy forming poorly rooted plants like Ceratophyllum demersum and Lemna trisulca. Small floating lemnids may also be abundant. This community may persist under near brackish conditions despite large phytoplankton densities.

Diversity Expected numbers of species are specified. The number should be that encountered on a sampling visit and on inspection of about $10 \%$ of the lake area, not a number compiled from records over a long period or exhaustive survey. The absolute diversities obtained in these ways will be higher than the numbers specified in this Scheme. The presence of aggressive alien species is recognized by downgrading the otherwise determined quality by one class.

Abundance

0: no plants visible, nothing on rake.

1: some plants visible but sparse, some plants on rake.

2: plants present, many rakes produce plant samples (up to 70\%) and plants do not interfere with boat movement (PVI up to approx. 25\%).

3: plants obvious with most rakes producing plant samples $(>70 \%)$, plants may interfere with boat movement in places (approx. PVI > 25\%).

(d) Macroinvertebrates

Ten stems of the characteristic emergent macrophyte species should be cut at sediment level in each of four locations in the lake and gently scraped free of animals into a jar of ethanol. They should be examined under a stereomicroscope and classified to family, or group in the case of chironomids. Counts should be classified also as predators and nonpredators. Ten soft-bottom samples from the littoral zone should be taken with a corer to about $10 \mathrm{~cm}$, sieved through $240 \mu \mathrm{m}$ mesh and preserved for examination in ethanol. Total oligochaetes and total chironomids should be counted.

(e) Fish

Fish should be sampled by methods acceptable in the local community, in such a way as to give estimates per unit area of total biomass and of piscivores and non-piscivores. Species should be identified and local information used to compile the full species list because any fishing operation is likely to be selective. Symbols used are: Pi (native piscivores present), Abex (introduced aggressive species absent), Altd (either native piscivores absent or aggressive introduced species present).

(f) Hydromorphological and other features

Quantity and dynamics of water flow, residence time

Normal (N): There are no significant schemes for abstraction or addition of water by human activities. Significant means that more than $5 \%$ of the long-term average natural water throughput is changed as a result of human activities. This is within normal variation but not so great that the system would be damaged in an extreme year.

Modified (M): More than 5\% of the long-term average natural total water throughput is added or removed by human activities but less than $10 \%$.

Severely modified (SM): More than $10 \%$ of the long-term average natural water throughput is added or removed by human activities.

Connection to groundwater

Normal (N): No groundwater abstraction within the catchment

Modified (M): Groundwater abstraction leading to changes in lake level that are within 10\% of the normal lake level variation, measured as the long-term mean range in lake level change.

Severely modified (SM): Groundwater abstraction leading to changes in water level that are more than $10 \%$ of the normal lake level variation, measured as the long-term mean range in lake level change. 
Lake depth variation

Undisturbed (U): Catchment vegetation is natural or semi-natural, unimproved by fertilization for domestic stock and not cleared for cultivation or urban development.

Disturbed (D): There is some intensive grazing or clearance but of less than $50 \%$ of the catchment.

Severely disturbed (SD): There is grazing or clearance of more than $50 \%$ of the catchment.

Quantity, structure and substrate of the lake bed

Undisturbed (U): No removal of substrates or dumping of them by human activities.

Disturbed (D): Minor removal of substrates or dumping of substrates, affecting less than $1 \%$ of the lake area.

Severely disturbed (SD): Removal of substrates or dumping of them, affecting more than $1 \%$ of the lake area.

Structure of the lake shore

Intact (I): No development of the shoreline and no damage that is permanent (spontaneously repairable within one year). No alien emergent species of a problematic nature (invasive, suppressive species). Exotic species that are not considered problematic may be present.

Developed (D): Up to $5 \%$ of the shoreline no longer occupied by natural vegetation or permanently damaged or occupied by problematic invasive alien emergent species.

Heavily developed (HD): 5-30\% of the shoreline no longer occupied by natural vegetation or permanently damaged or occupied by emergent, invasive, alien species.

Severely developed (SD): More than 30\% of the shoreline no longer occupied by natural vegetation or permanently damaged or occupied by problematic invasive alien emergent species.

Temperature

Undisturbed (U): There are no anthropogenic discharges of water or removals of inflow water that would alter the natural temperature of the lake.

Disturbed (D): There are anthropogenic discharges of water or removals of inflow water that alter the mean annual lake temperature by up to $2.5^{\circ} \mathrm{C}$.

Severely disturbed (SD): There are anthropogenic discharges of water or removals of inflow water that alter the mean annual lake temperature by more than $2.5^{\circ} \mathrm{C}$.

Oxygen

Undisturbed (U): There are no anthropogenic sources of discharge to the lake that would cause deoxygenation.

Moderately disturbed (MD): There are sources of anthropogenic discharge of deoxygenating substances that are recognizable, reduce the oxygen concentration of the local water below natural saturation levels but which have no long-term or extensive effects.

Disturbed (D): There are sources of anthropogenic discharge of deoxygenating substances that are obvious and reduce the oxygen concentrations of parts of the lake beyond the local area of the inflow or discharge point and have semi-permanent or permanent effects.

Severely disturbed (SD): There are sources of anthropogenic discharge that are obvious and permanently reduce the oxygen concentrations over large areas.

Salinity

Uncontaminated (U): There is no contamination, from human activities, of the lake with water of distinctly different salinity than that which would be expected in the natural state.

Moderately contaminated (MC): There is contamination, from human activities, of the lake with water of distinctly different salinity from that which would be expected in the natural state, leading to deviations of up to $50 \%$ from the natural state, as determined from uncontaminated water in the general area.

Contaminated (C): There is contamination, from human activities, of the lake with water of distinctly different salinity from that which would be expected in the natural state, leading to deviations of up to $100 \%$ (i.e doubling or halving) from the natural state, as determined from uncontaminated water in the general area.

Severely contaminated (SC): There is contamination, from human activities, of the lake with water of distinctly different salinity from that which would be expected in the natural state, leading to deviations of more than $100 \%$ from the natural state, as determined from uncontaminated water in the general area.

Pollution by other substances

This variable would be very expensive to determine exhaustively. The presumption is that the lake is unpolluted unless there is reason to believe otherwise from activities close to it or prominent in the catchment. In such a case, specialist investigations will have to be carried out. It may be presumed, however, that polluting substances will inevitably be present to some extent if any of the catchment is industrial or used for intensive husbandry or agriculture.

Unpolluted (U): Concentrations of substances listed in Annex VIII (other than nutrients, natural deoxygenating substances, natural suspended solids and required heavy metal metabolites) are close to zero and below the limits of detection of the most advanced techniques in use. 
Moderately polluted (MP): Concentrations of substances listed in Annex VIII (other than nutrients, natural deoxygenating substances, and natural suspended solids and required heavy metal metabolites) are lower than the NOEC concentrations, weighted by safety factors and determined by the procedure set out in Section 1.2.6 of Annex V.

Polluted (P): Concentrations of substances listed in Annex VIII (other than nutrients, natural deoxygenating substances, and natural suspended solids) are greater than those determined by the procedure set out in Section 1.2.6 of Annex V. Heavy metals required as metabolites may be present at higher concentrations and are excluded unless there is an overt discharge of such substances from an anthropogenic source.

\section{Instructions for using scheme}

1. Obtain the appropriate data from the lake.

2. Select the appropriate ecotype in Appendix 2, using information on climate, area, catchment geology and conductivity.

3. For each variable in turn, compare the measured value with the range of values given for the ecotype and determine the ecological status (high to bad) for that variable. This is straightforward in most instances, but for low conductivity lakes where there may be simultaneous effects of acidification and eutrophication, there may be alternative statuses for a variable, dependent on $\mathrm{pH}$. The appropriate $\mathrm{pH}$ values are indicated.

4. First examine the biological variables (those relating to phytoplankton, zooplankton, macrophytes, invertebrates, fish and shoreline structure) and proceed through steps 5-8.

5. Sum the number of biological variables classified as high status. If these constitute more than $80 \%$ of the available biological variables, the lake is accorded high ecological status and you should go to step 9 . If they constitute less than $80 \%$, go to step 6 .

6. Sum the number of biological variables classified as either high or good status. If these constitute more than $80 \%$ of the available biological variables, the lake is accorded good ecological status status and you should go to step 9 . If they constitute lower than $80 \%$, go to step 7 .

7. Sum the number of biological variables classified as any of high, good or moderate status. If these constitute more than $80 \%$ of available biological variables, the lake is accorded moderate ecological status and you should go to step 9. If they constitute less than $80 \%$, go to step 8 .

8. Sum the number of biological variables classified as any of high, good, moderate or poor status. If these constitute more than $80 \%$ of available biological variables, the lake is accorded poor ecological status. If they constitute less than $80 \%$, the lake is accorded bad ecological status.

9. Repeat steps 5-8 for all of the variables (biological, chemical and hydromorphological) and classify the lake on the basis of all variables.

10. Compare the classifications based on biological and on all variables and accept the lesser of the two estimates. The percentage of variables achieved for this or a higher category constitutes the probability that the lake truly falls into that category.

\section{APPENDIX 2. THE ECOFRAME SCHEME}

Version 8, for assessment of ecological status in shallow lakes. The criteria for achieving a given ecological status are given for the 48 ecotypes in the scheme. 


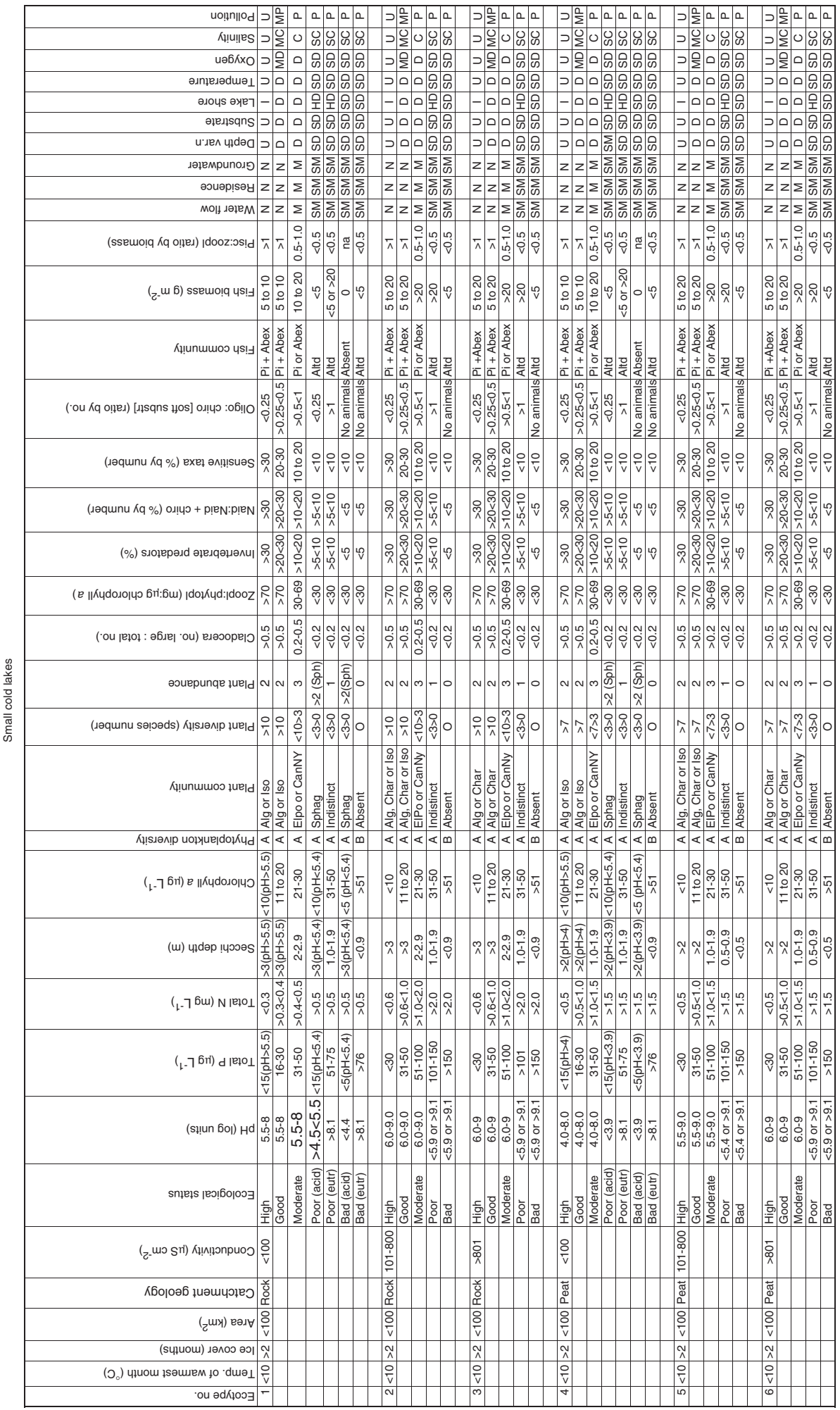




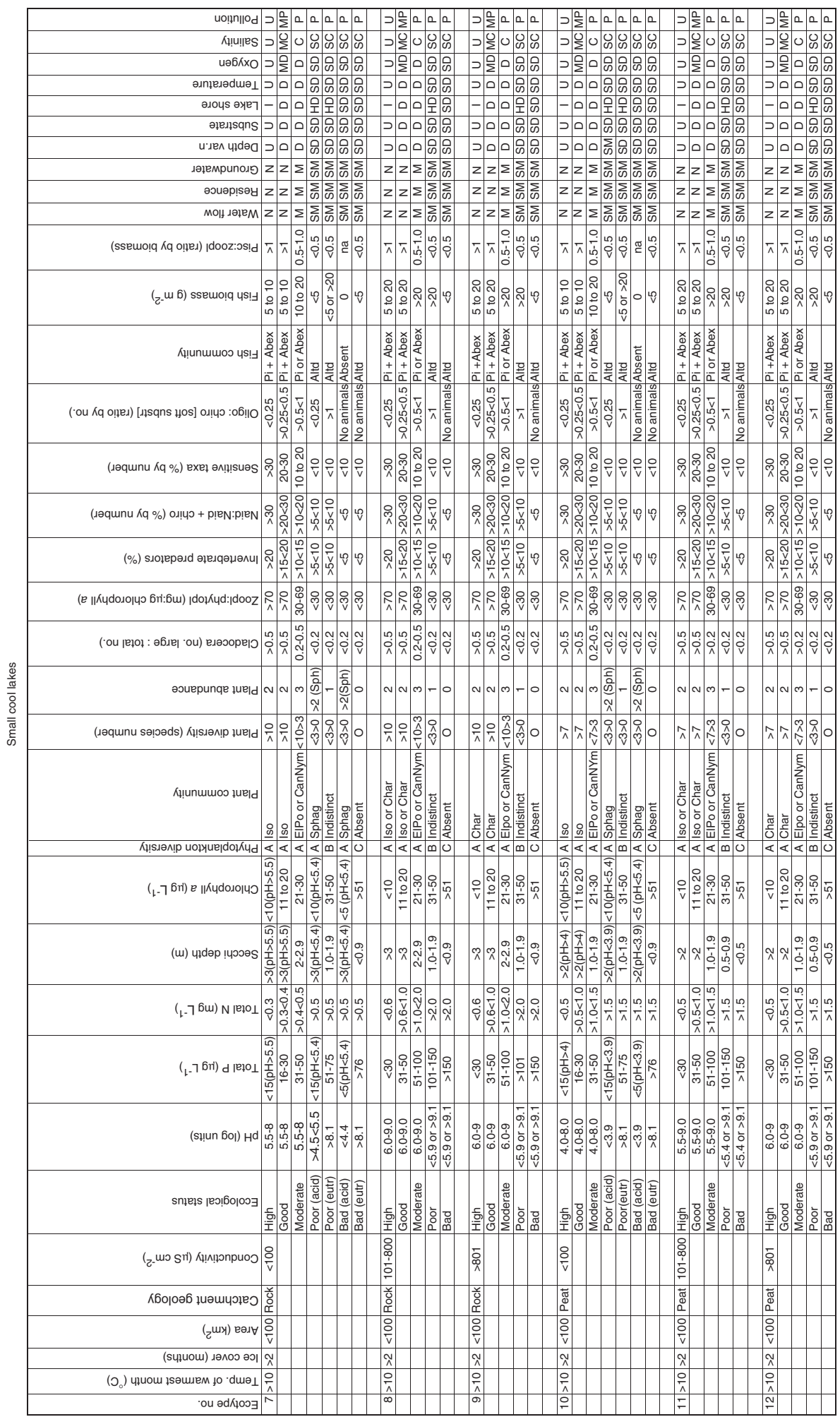




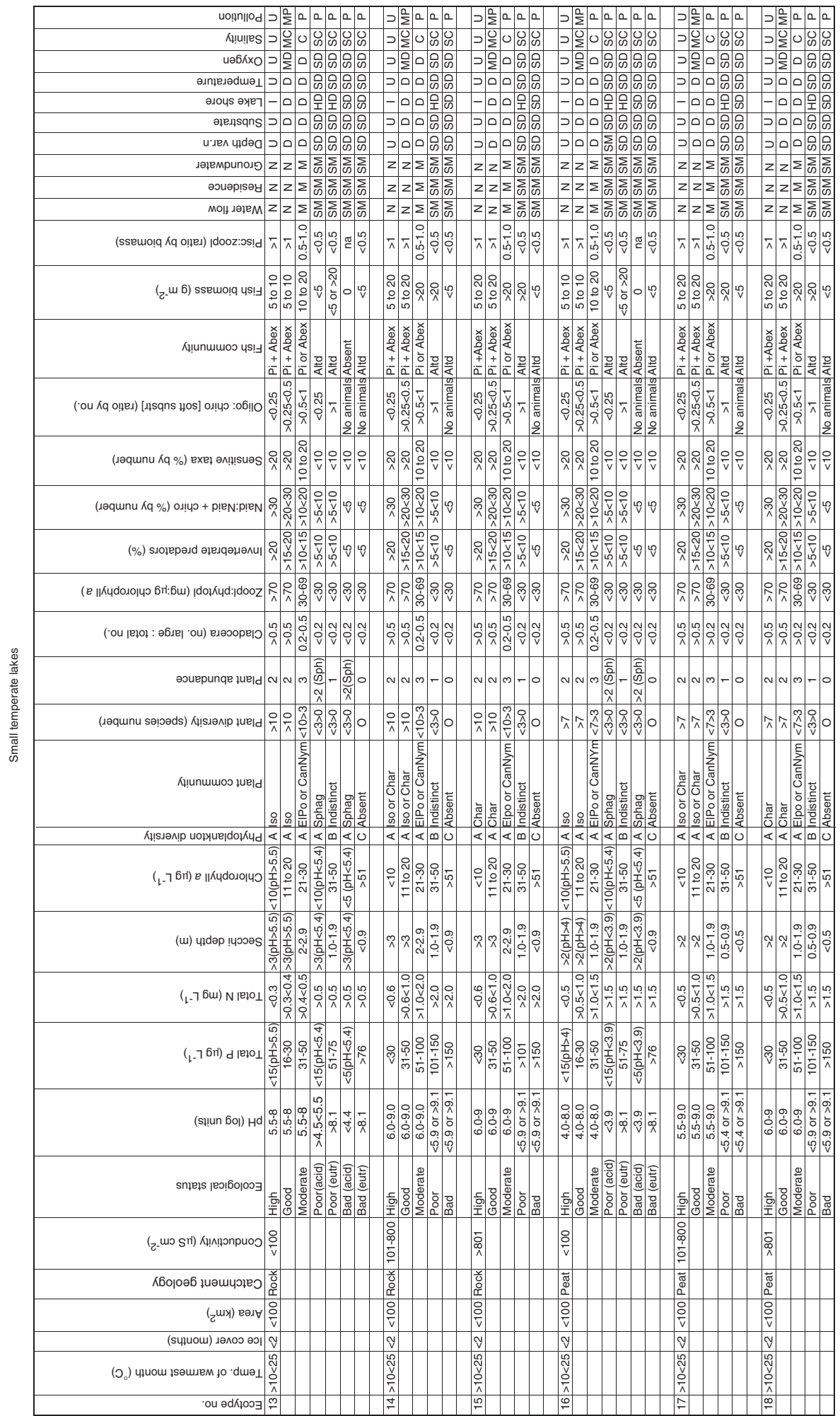




\begin{tabular}{|c|c|c|c|c|c|c|}
\hline uol!nn॥णd & 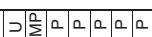 & 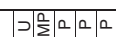 & 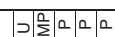 & 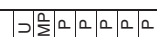 & 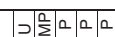 & 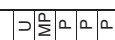 \\
\hline Kilu||es & 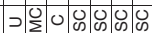 & $\supset$ ¿ & $\supset$ OU. & $\supset$ Ju 0 O & 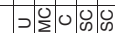 & 30 \\
\hline 4อ6 $6 \times 0$ & 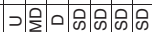 & $\supset \sum \Delta$ की & $\supset \sum \circ$ कीके & 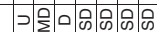 & วहै०कीके के & $\partial$ \\
\hline әлицедәdшәІ & ग००कीकिकीकि & ग० $\triangle$ किके & ग० $\triangle$ किके & ग० $\triangle$ किकिकिके & ग००कीके & 20 \\
\hline әочч әует & - 0 -O全全的的 & -00 全它 & -0 - 全酋 & -00 I全命的 & $-\Delta \Delta$ 空的 & -0 \\
\hline 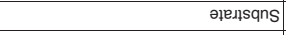 & 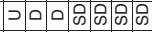 & 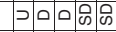 & 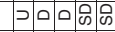 & 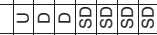 & $\supset \triangle \triangle$ किकि & 300 \\
\hline u'den yidea & 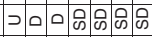 & 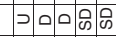 & $\supset \triangle \triangle$ किके & 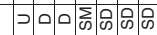 & $\supset \square \triangle 0$ के के & 30 \\
\hline дәңемрипод & $z z \sum \sum_{\infty} \sum_{\infty} \sum_{\infty} \sum_{\infty}$ & $z z \sum \sum \sum_{\infty} \sum_{\infty}^{5}$ & $z z \sum \sum_{\infty} \sum_{\infty}$ & $z z \sum \sum \sum_{\infty} \sum_{\infty} \sum_{\infty}^{n} \sum_{\infty}^{5}$ & $z z \sum \sum_{0}^{\sum} \sum_{\infty}^{5}$ & $z$ \\
\hline әэиәр!sәу & $z z \sum \sum \sum_{\infty} \sum_{\infty} \sum_{\infty} \sum_{\infty}$ & $z z \sum \sum \sum_{\infty} \sum_{\infty}^{5}$ & $z z \sum \sum_{\infty} \sum_{\infty}^{5}$ & $z z \sum \sum_{\infty} \sum_{\infty} \sum_{\infty} \sum_{\infty}$ & $z z \sum \sum \sum_{\infty} \sum_{\infty}^{5}$ & $z$ \\
\hline м이치리 M & $z z \sum \sum_{\infty} \sum_{\infty} \sum_{\infty} \sum_{\infty}$ & $z z \sum \sum \sum_{\infty} \sum_{\infty}^{5}$ & $z z \sum \sum \sum_{\infty} \sum_{\infty}$ & $z z \sum \sum \sum \sum \sum \sum \sum \sum \infty$ & $z z=\sum \sum \sum \sum_{\infty}$ & $2 z$ \\
\hline 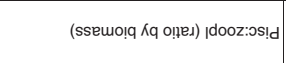 & 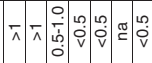 & 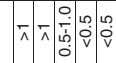 & 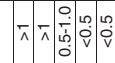 & 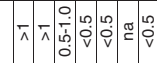 & 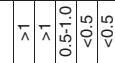 & in \\
\hline (z-w 6) ssemo!̣ ys! & 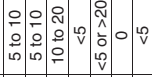 & 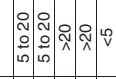 & 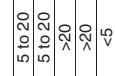 & 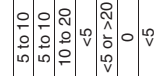 & 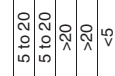 & \\
\hline Kł! unmwor ys!y & 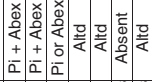 & 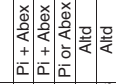 & 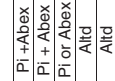 & 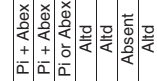 & 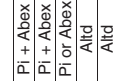 & \\
\hline 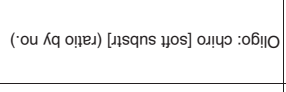 & 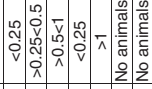 & 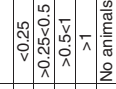 & 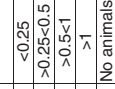 & 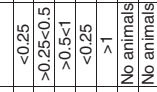 & 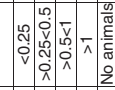 & \\
\hline 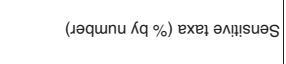 & 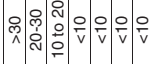 & 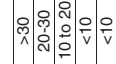 & 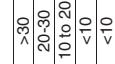 & 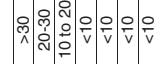 & : & \\
\hline 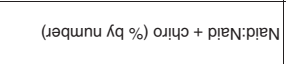 & 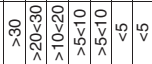 & 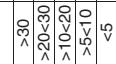 & 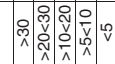 & 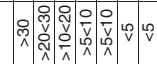 & 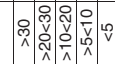 & \\
\hline (\%) s.ołepә.d әңедаәнәли| & 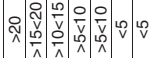 & 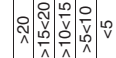 & 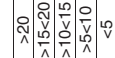 & 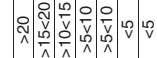 & 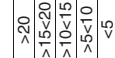 & \\
\hline (:6m) |dołKud:Idooz & 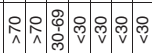 & 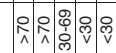 & 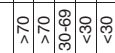 & 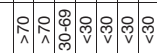 & 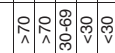 & \\
\hline 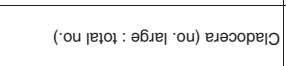 & 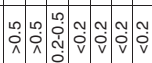 & 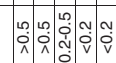 & 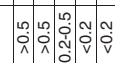 & 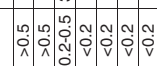 & 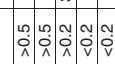 & \\
\hline әәиерunqe tue|d & 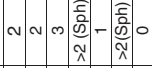 & a & $\mathrm{n}$ & 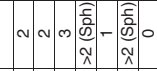 & & \\
\hline 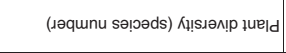 & 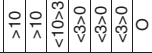 & 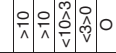 & 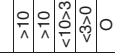 & 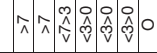 & 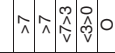 & $\wedge \lambda$ \\
\hline 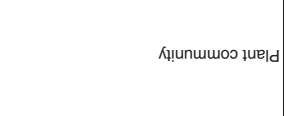 & 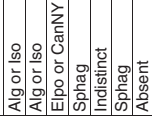 & 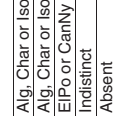 & 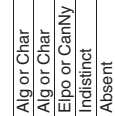 & 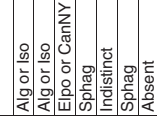 & 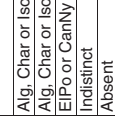 & \\
\hline 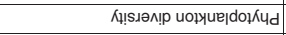 & $\varangle<\varangle<\infty<0$ & $<<<\infty 0$ & $\varangle<\varangle \infty 0$ & $\varangle<\varangle<\infty<0$ & $\varangle<\ll \infty 0$ & $\varangle<\varangle \infty 0$ \\
\hline 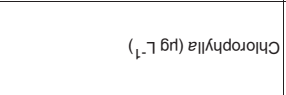 & 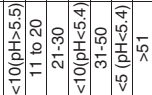 & $\left(\begin{array}{lll}0 \\
0 \\
\mathrm{v}\end{array}\right.$ & 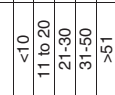 & 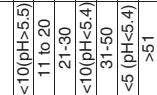 & 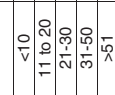 & \\
\hline 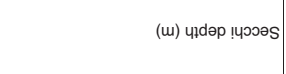 & 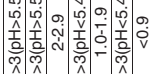 & 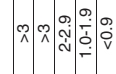 & 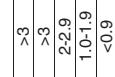 & 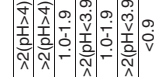 & 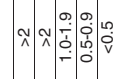 & \\
\hline$\left({ }^{2}-76 \mathrm{~m}\right) \mathrm{N} / \mathrm{etO \perp}$ & 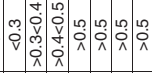 & 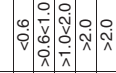 & 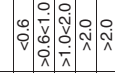 & 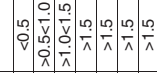 & 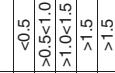 & 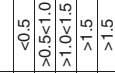 \\
\hline 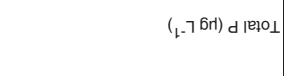 & 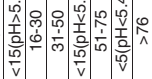 & 它 & 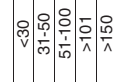 & 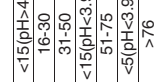 & 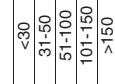 & \\
\hline (słlun 6ol) $\mathrm{Hd}^{\mathrm{d}}$ & 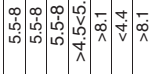 & 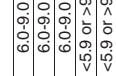 & 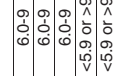 & 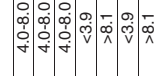 & 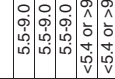 & \\
\hline snłets | & 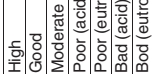 & 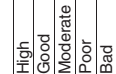 & 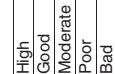 & 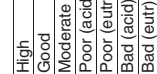 & 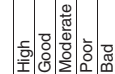 & \\
\hline 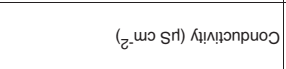 & $\frac{8}{v}$ & 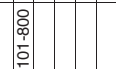 & $\left|\begin{array}{l}\overline{0} \\
\mathbf{D} \\
\Lambda\end{array}\right|$ & $\frac{8}{v}$ & $\mid \begin{array}{l}0 \\
0 \\
0 \\
\vdots \\
0 \\
0\end{array}$ & 市 \\
\hline Кбороәб ұиәшчગ્ว & & 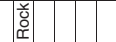 & $\mid \begin{array}{l}x \\
0 \\
0 \\
\end{array}$ & $\mid \begin{array}{l}\pi \\
\bar{d} \\
0\end{array}$ & $\mid \begin{array}{c}\pi \\
\bar{d} \\
0\end{array}$ & $\mid \begin{array}{c}\pi \\
\bar{d} \\
0\end{array}$ \\
\hline 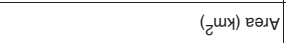 & & $\frac{8}{1}$ & $\frac{8}{x}$ & $\frac{8}{1}$ & $\frac{8}{\wedge}$ & $\frac{8}{\lambda}$ \\
\hline 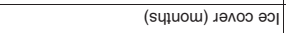 & & $\pi$ & $\pi$ & $\pi$ & $\pi$ & $\pi$ \\
\hline 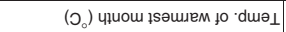 & & $\frac{0}{v}$ & $\frac{0}{v}$ & $\frac{0}{v}$ & $\frac{0}{v}$ & $\frac{0}{v}$ \\
\hline 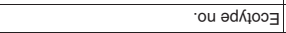 & & i & $\hat{\mathrm{N}}$ & $\stackrel{\infty}{i}$ & i & i \\
\hline
\end{tabular}




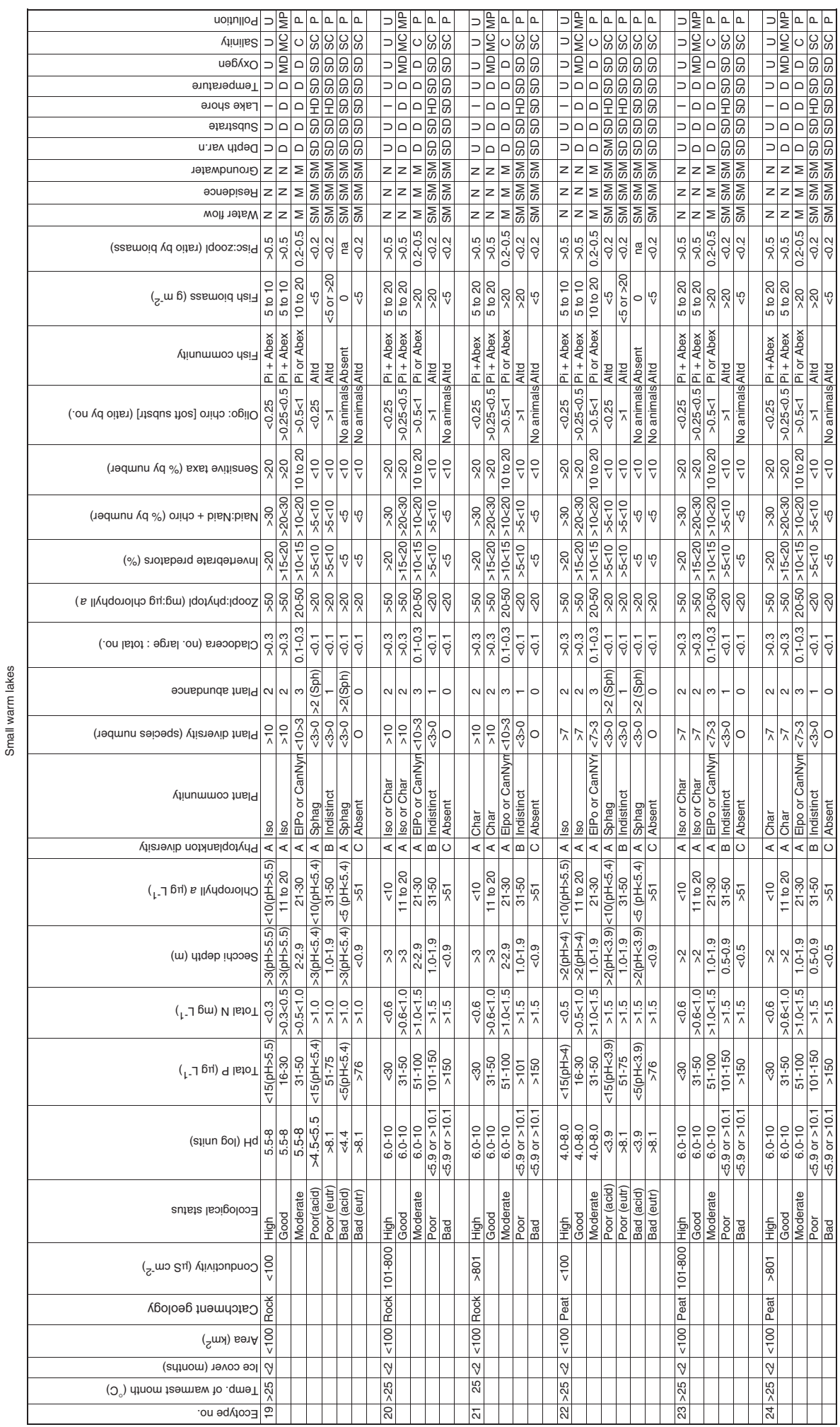




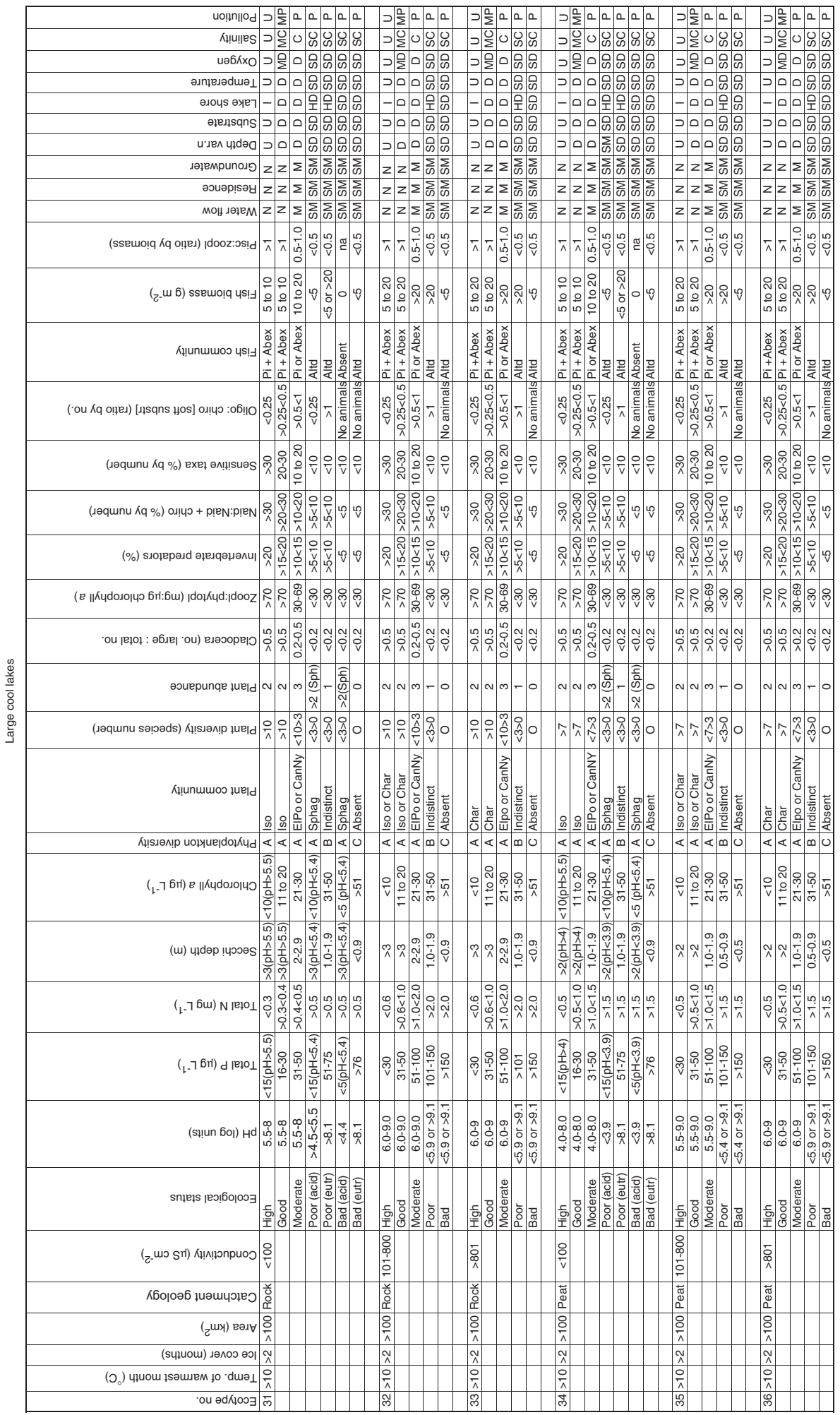




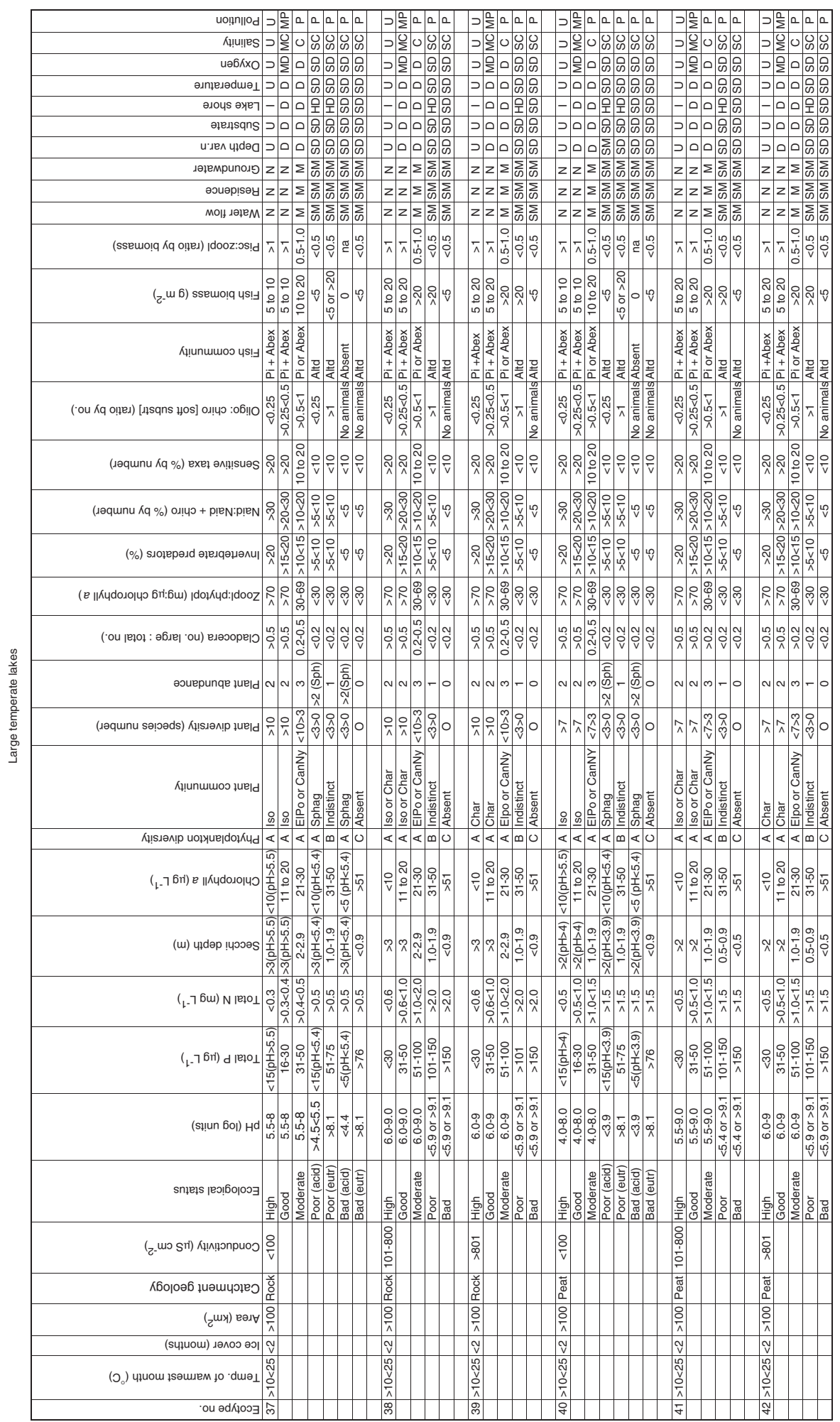




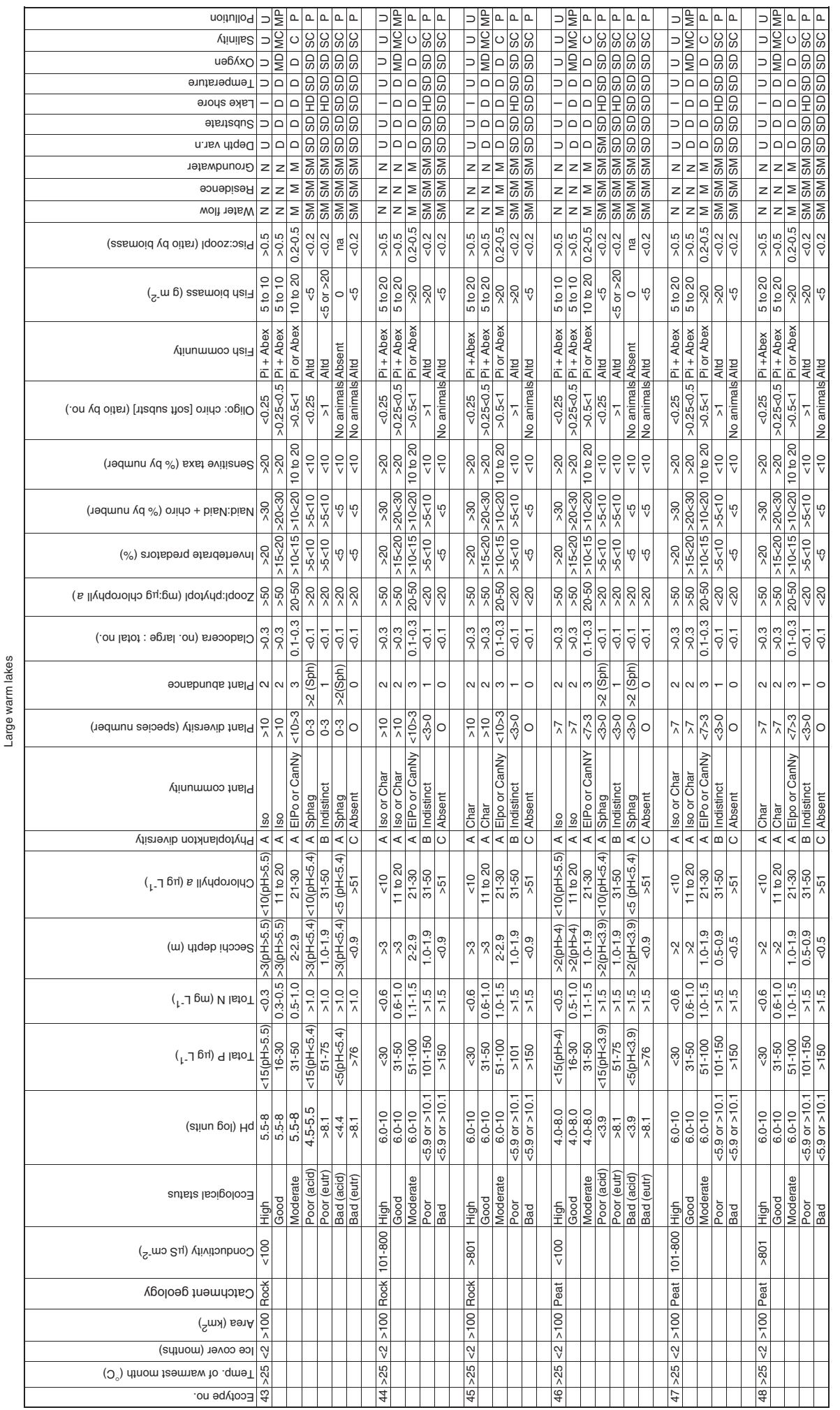

